\title{
Physicochemical and pathohistological changes in experimental fibrosarcoma tumors of hamsters treated with metformin and itraconazole
}

\author{
KOSTA J. POPOVIĆ ${ }^{1}$, DUŠICA J. POPOVIĆ ${ }^{2}$, DEJAN MILJKOVIĆ ${ }^{2}$ \\ DUŠAN LALOŠEVIĆ ${ }^{2}$, IVAN ČAPO ${ }^{2}$ and JOVAN K. POPOVIĆ ${ }^{3}$ \\ Departments of ${ }^{1}$ Pharmacy, ${ }^{2}$ Histology and Embryology, and ${ }^{3}$ Pharmacology, Toxicology and Clinical Pharmacology, \\ Faculty of Medicine, University of Novi Sad, 21000 Novi Sad, Republic of Serbia
}

Received October 17, 2018; Accepted May 14, 2019

DOI: $10.3892 / \mathrm{ol} .2019 .10509$

\begin{abstract}
The anticancer effects of metformin (an antihyperglycaemic agent) and itraconazole (an antifungal agent), which are established non-oncologic drugs, were investigated in the present study. The weight, diameter, volume, density, surface, surface to volume ratio and immunohistochemistry of experimental fibrosarcoma tumors were investigated in hamsters treated with metformin and itraconazole. Briefly, the hamsters were injected with BHK-21/C13 cells in order to induce fibrosarcoma, and the animals were treated daily with metformin, itraconazole or a combination of the two drugs. Subsequently, blood samples were obtained for biochemical analyses and the tumors were excised, weighed and measured. The tumor samples were pathohistologically and immunohistochemically assessed for proliferation marker protein $\mathrm{Ki}-67$, hematopoietic progenitor cell antigen $\mathrm{CD} 34$, cytochrome $c$ oxidase subunit 4 (COX4), glucose transporter 1 (GLUT1) and inducible nitric oxide synthase (iNOS), and vital organs were toxicologically tested. Ki-67-positivity and cytoplasmic marker (CD34, COX4, GLUT1, iNOS) immunoexpression in the tumor samples were quantified. The results revealed that the combination of metformin and itraconazole significantly altered the physicochemical and pathohistological characteristics of the hamster fibrosarcoma tumors, including absolute and relative weight, volume, density, length, surface area, surface to volume ratio, $\mathrm{Ki}$-67-positivity and the immunoexpression of cytoplasmic markers, without indications of toxicity. Furthermore, metformin with itraconazole demonstrated antiproliferative functions in cervical carcinoma HeLa, colon carcinoma
\end{abstract}

Correspondence to: Professor Jovan K. Popović, Department of Pharmacology, Toxicology and Clinical Pharmacology, Faculty of Medicine, University of Novi Sad, 3 Hajduk Veljkova, 21000 Novi Sad, Republic of Serbia

E-mail: jovan.popovic@mf.uns.ac.rs

Key words: metformin, itraconazole, hamsters, BHK-21/C13, fibrosarcoma
HT-29, lung carcinoma A549 and fibrosarcoma BHK-21/C13 cells, with markedly lower cytotoxicity in the normal fetal lung MRC-5 cells. In conclusion, the administration of metformin in combination with itraconazole may inhibit the growth of fibrosarcoma tumors in vivo and the proliferation of various malignant cell lines in vitro, suggesting that this may be an effective and safe approach as a nontoxic anticancer adjuvant and relapse prevention therapy.

\section{Introduction}

Metformin, a standard clinical drug, used for the treatment of type 2 diabetes mellitus and polycystic ovary syndrome, reduces cellular energy production and inhibits growth of various cultured cancer cell lines $(1,2)$. Metformin has certain anticancer effects on BHK-21/C13-induced fibrosarcoma in hamsters (3). Notably, metformin exerts anticancer effects in vitro via the following main mechanisms: Inhibition of AMP-activated protein kinase (AMPK)/serine/threonineprotein kinase mTOR signaling, anti-angiogenesis, or folate and autophagy inhibition (3). The drug also exhibits anticancer effects by altering host response mechanisms, decreasing gluconeogenesis and regulating circulating insulin, lipid metabolism and serum bile acids (4). In addition, other possible anticancer mechanisms of action have been identified for metformin, including transcriptional regulation of certain genes (5), cobalamin deficiency (6), inhibition of neurogenic locus notch homolog protein 1/transcription factor HES and androgen receptor signaling pathways (7), and regulation of tight junctions via the myosin light-chain kinase-MLC signaling pathway (8).

In patients with diabetes, metformin is usually administered in combination with the most common and safe antimycotic agent itraconazole, since fungal infections occur frequently in diabetes (9). This combination is nontoxic in humans (10).

Similar to metformin, itraconazole also possesses anticancer properties. The in vitro anticancer functions of itraconazole in cancer cell cultures include the following: Inhibition of AMPK/mTOR signaling (11), anti-angiogenesis (11), antilymphangiogenesis (11), folate and autophagy inhibition $(11,12)$, inhibition of Hedgehog signaling $(13,14)$, 
inhibition of P-glycoprotein (P-gp), chemosensitization (reversed multiple drug resistance, particularly to cytotoxic antitumor drugs), inhibition of the transportation and pumping of cholesterol, and inhibition of the Wnt/ $\beta$-catenin signaling pathway (11). There is notable synergy between antifolates and itraconazole, which inhibits ergosterol biosynthesis (12).

The pharmacokinetic interaction between metformin and itraconazole by mutual competitive inhibition of metabolism through hepatic and intestinal cytochrome P450 3A (CYP3A)1/2 leads to a significant increase in the areas under the serum concentration/time curves of metformin and itraconazole following oral or intravenous (IV) administration in rats, implying an improved effect of the drugs $(15,16)$. Metformin and itraconazole are metabolized by the CYP3A subfamily in rats and humans; the two drugs have been demonstrated to significantly inhibit the metabolism of each other by CYP3A4 in human microsomes (15). In humans, metformin is predominantly excreted in urine unchanged, with $<20 \%$ of the IV dose being metabolized (15). In contrast, itraconazole is eliminated exclusively by hepatic metabolism, where CYP3A4 in humans or CYP3A1/2 in rats is involved to produce several metabolites, including 7-hydroxyitraconazole, the major metabolite in both species (15).

Itraconazole inhibits P-gp, decreasing the elimination of organic cation drugs and increasing their absorption (11). Metformin is present as a cation at physiological pH (17). Organic cation transporters 1 and 3 are active transporters of metformin (18); therefore, as a potent P-gp and CYP3A4 inhibitor, itraconazole can increase the plasma concentrations of P-gp and CYP3A4 substrates, including metformin, and enhance their effects (19).

The aim of the present study was to investigate the anticancer effects of combining nontoxic drugs on experimental tumors. Preclinical and limited clinical studies have proposed the use of metformin (3) or itraconazole (11) as promising nontoxic anticancer agents. To the best of our knowledge, no published results of the anticancer effect of the combination of these drugs exist to date. The possibilities of synergistic anticancer metformin-itraconazole interactions (15-18) and safe multitargeting therapy $(9,10)$, based on previous separate preclinical studies $(3,11,12)$, were the main reasons for testing this drug combination on an experimental hamster fibrosarcoma model.

Sarcoma models are of fundamental importance in cancer treatment research due to the multiple pathological and clinical entities, resistance to current therapies and high mortality attributed to these malignancies (20). Sarcomas are a large family of diverse mesenchymal malignant tumors derived from connective and soft tissues, such as bone, muscle, cartilage, fat, vascular tissue, skin or hematopoietic tissue (21). Sarcomas affect 200,000 individuals worldwide each year and represent a higher percentage of overall cancer morbidity and mortality in children and adolescents compared with adults $(22,23)$. Sarcomas account for $>20 \%$ of all pediatric solid malignant cancers (24). Notably, osteosarcoma is the most common primary bone tumor and mainly affects adolescents and young adults (25), and rhabdomyosarcoma is the most common soft tissue sarcoma of childhood (26). There are $>100$ different histological subtypes of soft tissue sarcomas, which develop in a number of different locations and tissues (23). Fibrosarcoma, which is a common soft tissue sarcoma, accounts for $\sim 10 \%$ of all sarcomas and occurs at all ages; in children, the majority of tumors are diagnosed in the first year and tend to occur in the lower extremities, whereas head and neck lesions account for $\leq 20 \%$ of cases. Despite treatment protocols that combine chemotherapy, including methotrexate, cisplatin, doxorubicin and ifosfamide, surgery and radiotherapy, the 5-year survival rate for patients diagnosed with sarcoma is $\sim 60 \%$, whereas for patients with metastatic disease the survival rate is $\sim 30 \%$. Current treatment strategies for sarcomas, including fibrosarcoma, are associated with significant side effects, and there have been no significant improvements in prognosis in the last decade (23). In addition, chemotherapy dose increase has not improved the outcome $(22,23)$. Therefore, there is a need for improved nontoxic therapies for the treatment of sarcoma and fibrosarcoma $(20,22,23)$. The main rationale for the use of metformin and itraconazole for separate or combined antisarcoma therapy in an animal fibrosarcoma model was the antifolate anticancer effect of the two drugs on malignant cells in vitro $(3,11,12)$. It was hypothesized that an interaction between the folic acid cycle and these drugs, which is different from the effects of the antifolate drug methotrexate, may produce synergistic anticancer effects similar to this antifolate drug, without toxicity.

To validate the results on tumor progression obtained by the measurements of fibrosarcoma dimensions, markers of cancer mitosis (proliferation marker protein $\mathrm{Ki}-67$ ), vasculature (hematopoietic progenitor cell antigen CD34), apoptosis [cytochrome $c$ oxidase subunit 4 (COX4)], glucose metabolism [glucose transporter 1 (GLUT1)] and nitric oxide (NO) production [inducible NO synthase (iNOS)] were immunohistochemically assessed in fibrosarcoma specimens $(3,11,14)$. Ki-67 immunoexpression was evaluated by stained cell counting (3). The relative immunoexpression of GLUT1, iNOS, CD34 and COX4 markers was graded according to the portion of stained sample areas. For further validation of the results of co-treatment with metformin and itraconazole, the in vitro antiproliferative functions of the combination treatment in cervical carcinoma HeLa, colon carcinoma HT-29, lung carcinoma A549, fibrosarcoma BHK-21/C13 and normal fetal lung MRC-5 cells were tested.

\section{Materials and methods}

Animal model. The present study was performed on 48 Syrian golden hamsters (22 males and 26 females; age, 12-20 weeks; weight, $\sim 100 \mathrm{~g}$ ). The animals were obtained from the Pasteur Institute and were maintained under standard animal housing conditions at $25 \pm 2{ }^{\circ} \mathrm{C}$ and $60 \pm 2 \%$ humidity under a 12 -h light/dark cycle. The animals had ad libitum access to food and water.

The study protocol was conducted in accordance with the requirements of the national regulations for the handling of laboratory animals and the study was approved by the University of Novi Sad Animal Ethics Committee (approval no. 01-78/18-5; dated April 26, 2016).

The hamsters were randomized into eight groups ( $\mathrm{n}=6$ hamsters/group) with equal numbers of males and females due to the potential role of sex hormones on the response to the treatment. Treatment with metformin, itraconazole 

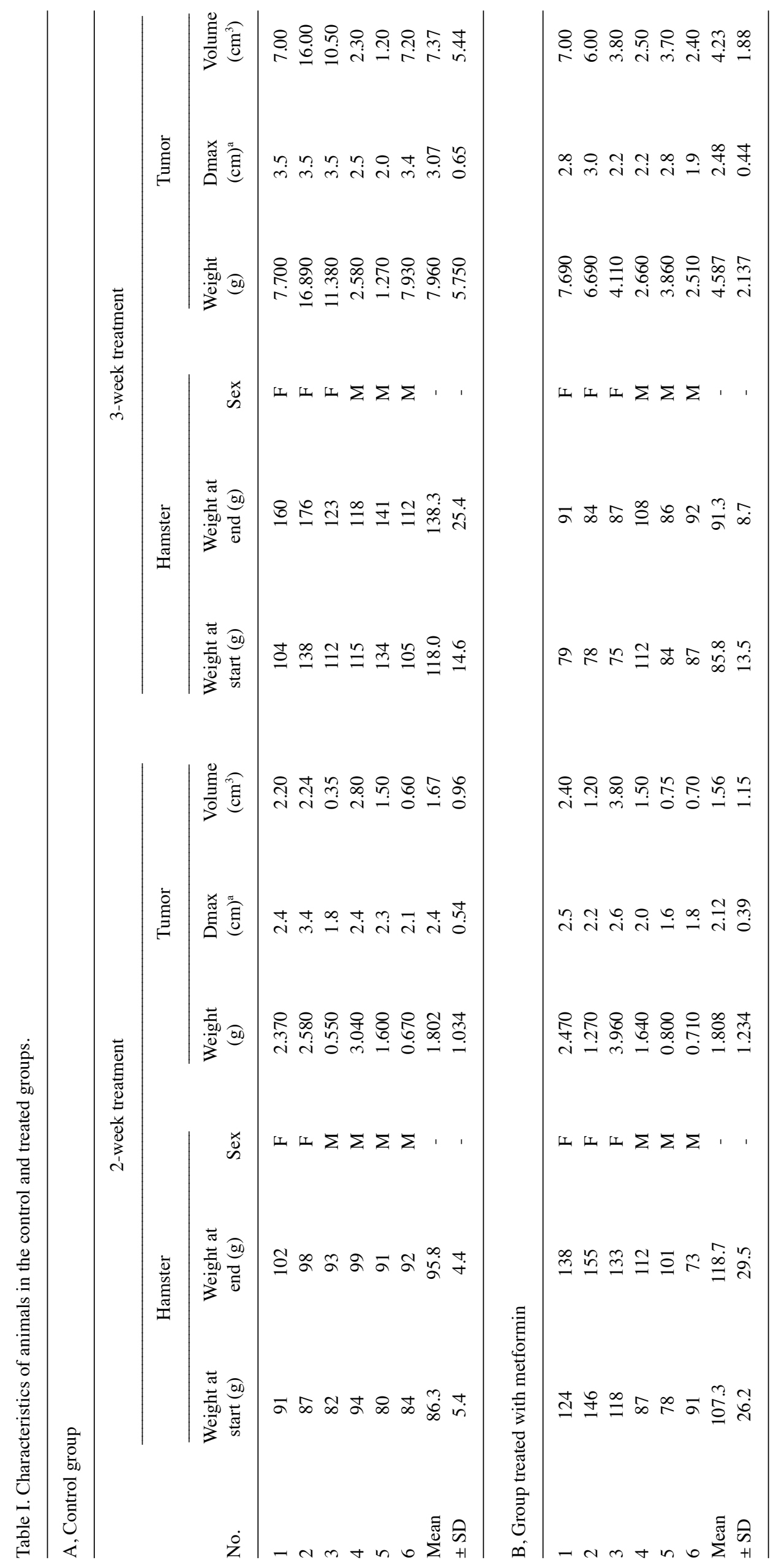

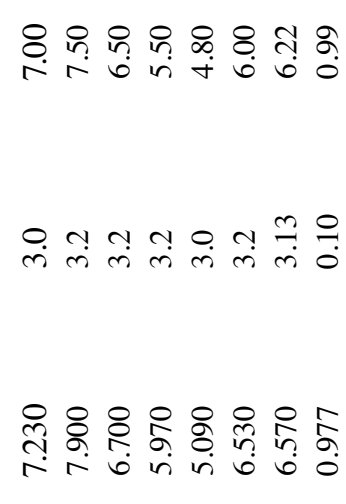

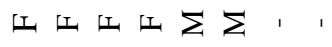

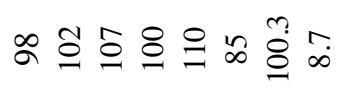

ฉ

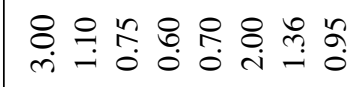

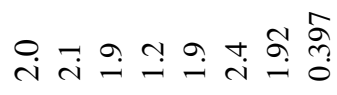

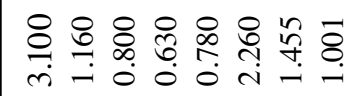

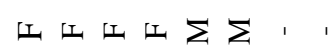

을워

สญำ จำ

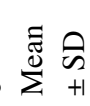


(both Galenika a.d.) and their combination in experimental groups was initiated 3 days prior to the subcutaneous inoculation of $1 \mathrm{ml}$ BHK-21/C13 cell suspension (27) $\left(2 \times 10^{6}\right.$ cells $\left./ \mathrm{ml}\right)$ into the back for the development of a subcutaneous fibrosarcoma tumor (28). BHK-21/C13 cells were cultured in DMEM media with $4.5 \mathrm{~g} / 1$ glucose (Capricorn Scientific), supplemented with $10 \%$ fetal bovine serum (FBS; Capricorn Scientific), $2 \mathrm{mM}$ glutamine (Capricorn Scientific) and $1 \%$ penicilin/streptomicin (Capricorn Scientific), at $37^{\circ} \mathrm{C}$, in a $5 \% \mathrm{CO}_{2}$ humidified atmosphere Cells were subcultured twice a week once they reached confluency of $70-80 \%$. Tumor inoculation and drug administration were performed by the same researcher to maintain consistency. The following humane endpoints were established: Significant body weight loss (20\%), decreased activity/responsiveness with loss of body weight, impaired posture, inability to eat, urinate or defecate, tumor diameter $>10 \%$ body weight, or tumor ulceration. The following aspects were monitored: Behavior, general condition, body weight (measured daily), general clinical signs (diarrhea, neurological signs, breathing disorders), tumor diameter, anatomical location, incidence of multiple tumors and tumor ulceration.

Two sets of experiments were performed. The first set involved four groups of animals administered different treatments via a gastric probe daily for 3 days prior to cancer cell inoculation: Perioral treatment with i) physiological saline; ii) $500 \mathrm{mg} / \mathrm{kg}$ metformin; iii) $250 \mathrm{mg} / \mathrm{kg}$ itraconazole; or iv) combination of $500 \mathrm{mg} / \mathrm{kg}$ metformin and $250 \mathrm{mg} / \mathrm{kg}$ itraconazole. The animals were sacrificed 2 weeks post-inoculation. The second set of experiments followed the same protocol as the first set, with the exception that the daily dose of metformin was $250 \mathrm{mg} / \mathrm{kg}$ and the animals were sacrificed at 3 weeks. To sacrifice the animals, a dose of $60 \mathrm{mg} / \mathrm{kg}$ pentobarbital was administered intraperitoneally. The animals were assessed for loss of consciousness at 5 min by a combination of methods, including a toe pinch, lack of visible respiration and lack of reaction on digital palpation. An additional dose of $30 \mathrm{mg} / \mathrm{kg}$ pentobarbital was administered if loss of consciousness was not observed. Total cardiac exsanguination was performed immediately following confirmation of loss of consciousness. The volume of blood extracted by total cardiac exsanguination was 3-5.5 ml, depending on animal weight and/or sex. Only 2-3 $\mathrm{ml}$ of the total collected blood was used for blood biochemical analysis. Following exsanguination and animal death, vital organs (heart, lungs, liver, kidneys and brain) were removed. The weight of the animals at the time of sacrifice is presented in Table I. In a previous study, subcutaneous inoculation of $1 \times 10^{7}$ BHK-21/C13 cells produced fibrosarcoma, which killed the animals in 40 days (28). Therefore, 21 days was the maximum duration of the experiments in the present study. All animals were in a good condition during the study, and none of the hamsters were euthanized prior to the end of the experiment. In the course of experiment, the tumor burdens were evaluated daily using calipers and the following ellipsoid volume formula: Volume $=4 \pi \mathrm{abc} / 3$, where $\mathrm{a}, \mathrm{b}$ and $c$ are half-diameters $(29,30)$. The maximal tumor burden in the present study, 1 day prior to sacrifice, was $<3.2 \%$ of body weight for the 2 -week treatment groups and $<10 \%$ of body weight for the 3-week treatment groups. After sacrifice, the tumors were excised, weighed, their diameters were measured 
Table II. Statistical evaluation of tumor characteristics following 2-week treatment.

Tumor (P-values)

\begin{tabular}{lcccccccc}
\cline { 2 - 7 } Group comparison & Weight & Relative weight & Volume & Density & Length & Surface area & Surface/volume & Mean Ki-67 \\
\hline C/M & 0.999 & 0.850 & 0.936 & $0.025^{\mathrm{a}}$ & 0.311 & 0.592 & $0.0499^{\mathrm{a}}$ \\
C/I & 0.610 & 0.862 & 0.600 & 0.450 & 0.170 & 0.251 & 0.250 \\
M/I & 0.615 & 0.950 & 0.803 & 0.410 & 0.472 & 0.590 & 0.110 & 0.999 \\
C/M+I & $0.009^{\mathrm{a}}$ & $0.01^{\mathrm{a}}$ & $0.0095^{\mathrm{a}}$ & $0.009^{\mathrm{a}}$ & $0.006^{\mathrm{a}}$ & $0.0085^{\mathrm{a}}$ & $0.049^{\mathrm{a}}$ & 0.850 \\
M/M+I & $0.019^{\mathrm{a}}$ & $0.0088^{\mathrm{a}}$ & $0.021^{\mathrm{a}}$ & 0.150 & $0.005^{\mathrm{a}}$ & $0.0078^{\mathrm{a}}$ & 0.601 & $0.035^{\mathrm{a}}$ \\
I/M+I & $0.029^{\mathrm{a}}$ & $0.037^{\mathrm{a}}$ & $0.0205^{\mathrm{a}}$ & $0.022^{\mathrm{a}}$ & $0.0085^{\mathrm{a}}$ & $0.0095^{\mathrm{a}}$ & 0.650 & $0.042^{\mathrm{a}}$
\end{tabular}

${ }^{a} \mathrm{P}<0.05$. C, control group; M, group treated with metformin $(500 \mathrm{mg} / \mathrm{kg}) ; \mathrm{I}$, group treated with itraconazole $(250 \mathrm{mg} / \mathrm{kg})$; $\mathrm{M}+\mathrm{I}$, group treated with the combination of metformin $(500 \mathrm{mg} / \mathrm{kg})$ and itraconazole $(250 \mathrm{mg} / \mathrm{kg})$.

Table III. Statistical evaluation of tumor characteristics following 3-week treatment.

\begin{tabular}{|c|c|c|c|c|c|c|c|c|}
\hline \multirow[b]{2}{*}{ Group comparison } & \multicolumn{8}{|c|}{ Tumor (P-values) } \\
\hline & Weight & Relative weight & Volume & Density & Length & Surface area & Surface/volume & Mean Ki-67 \\
\hline $\mathrm{C} / \mathrm{M}$ & 0.201 & 0.833 & 0.120 & 0.480 & 0.133 & 0.351 & $0.049^{\mathrm{a}}$ & 0.479 \\
\hline $\mathrm{C} / \mathrm{I}$ & 0.610 & 0.888 & 0.551 & 0.401 & 0.655 & 0.656 & $0.048^{\mathrm{a}}$ & 0.535 \\
\hline $\mathrm{M} / \mathrm{I}$ & 0.051 & 0.213 & $0.049^{\mathrm{a}}$ & 0.900 & $0.0095^{\mathrm{a}}$ & $0.019^{\mathrm{a}}$ & 0.713 & 0.803 \\
\hline $\mathrm{C} / \mathrm{M}+\mathrm{I}$ & $0.035^{\mathrm{a}}$ & $0.049^{\mathrm{a}}$ & $0.036^{\mathrm{a}}$ & $0.005^{\mathrm{a}}$ & $0.045^{\mathrm{a}}$ & $0.047^{\mathrm{a}}$ & $0.046^{\mathrm{a}}$ & $0.044^{\mathrm{a}}$ \\
\hline $\mathrm{M} / \mathrm{M}+\mathrm{I}$ & $0.018^{\mathrm{a}}$ & $0.015^{\mathrm{a}}$ & $0.015^{\mathrm{a}}$ & $0.035^{\mathrm{a}}$ & 0.062 & $0.008^{\mathrm{a}}$ & 0.452 & 0.053 \\
\hline $\mathrm{I} / \mathrm{M}+\mathrm{I}$ & $0.002^{\mathrm{a}}$ & $0.002^{\mathrm{a}}$ & $0.003^{\mathrm{a}}$ & $0.045^{\mathrm{a}}$ & $0.007^{\mathrm{a}}$ & $0.0001^{\mathrm{a}}$ & 0.552 & $0.021^{\mathrm{a}}$ \\
\hline
\end{tabular}

${ }^{\mathrm{a}} \mathrm{P}<0.05$. C, control group; M, group treated with metformin $(250 \mathrm{mg} / \mathrm{kg})$; I, group treated with itraconazole $(250 \mathrm{mg} / \mathrm{kg})$; M+I, group treated with the combination of metformin $(250 \mathrm{mg} / \mathrm{kg})$ and itraconazole $(250 \mathrm{mg} / \mathrm{kg})$.

and the exact tumor volume was determined using the standard water volume displacement method.

Metformin was dissolved in physiological saline and administered at a dose of 250 or $500 \mathrm{mg} / \mathrm{kg}$ (in $1 \mathrm{ml} / 100 \mathrm{~g}$ animal weight), equivalent to a human dose of 20 or $40 \mathrm{mg} / \mathrm{kg}$ (by normalization to surface area), which are the daily doses taken by patients with diabetes (31). The dose of itraconazole ( $250 \mathrm{mg} / \mathrm{kg}$ ) was equivalent to the maximum human dose of $20 \mathrm{mg} / \mathrm{kg}$, and was prepared and administered in the same manner as metformin. The control groups received physiological saline $(1 \mathrm{ml} / 100 \mathrm{~g}$ animal weight). The relative tumor weight was determined as the weight ratio of tumor/animal. The tumor volume was determined using the standard water volume displacement method, by measuring the water level in a graduated cylinder prior to and following the submergence of the tumor. The tumor density was calculated as density=mass/volume. The tumor surface area $(\mathrm{S})$ was calculated using the ellipsoid formula from three half diameters (a, b and $c): S=4 \pi\left\{\left[(a b)^{1.6}+(a c)^{1.6}+(b c)^{1.6}\right] / 3\right\}^{1 / 1.6}$. The ratio of tumor surface area to volume $(\mathrm{S} / \mathrm{V})$ was also calculated.

Tumor slices $(4 \mu \mathrm{m})$ were assessed pathohistologically and immunohistochemically for the verification of tumor growth and angiogenesis. The weight of the hamsters was recorded in order to evaluate possible side effects of metformin and/or itraconazole. The vital animal organs (brain, heart, lungs, liver and kidneys) were analyzed histopathologically and no obvious toxicological effects of drugs used in this experiment were detected.

Immunohistochemistry. In addition to the principal hematoxylin and eosin staining, immunohistochemical Ki-67, CD34, COX4, GLUT1 and iNOS staining was performed to assess tumor cell proliferation. Tissue sections were stained at room temperature with hematoxylin for $5 \mathrm{~min}$ and with Eosin $\mathrm{G}$ for $30 \mathrm{sec}$. For the Ki-67 staining, tumor slices were fixed in $10 \%$ neutral buffered formalin for $48 \mathrm{~h}$ at room temperature, blocked with $4 \%$ bovine serum albumin (Capricorn Scientific) in PBS for $1 \mathrm{~h}$ at room temperature, and incubated overnight at $4^{\circ} \mathrm{C}$ with anti-Ki-67 primary antibody (Thermo Fisher Scientific, Inc.; cat. no. RB-9043-P0, 1:300). Sections were incubated with fluorescein isothiocyanate-conjugated polyclonal anti-rabbit secondary antibody (cat. no. F7512; 1:80; Sigma-Aldrich; Merck KGaA) for $2 \mathrm{~h}$ at room temperature. The nuclei were counterstained with Hoechst 33256 (Sigma-Aldrich; Merck KGaA). In further immunohistochemical staining, the following primary antibodies were used: CD34 (Abcam; cat. no. ab81289; 1:200), COX4 (Abcam; cat. no. ab185056; 1:1,000), GLUT1 (Thermo Fisher Scientific, Inc.; cat. no. RB-9052-P0; 1:200) and iNOS (Thermo Fisher Scientific, Inc.; RB-9242-P0; 1:100). Briefly, sections (5 $\mu \mathrm{m})$ were deparaffinized in xylene $(100 \%)$ and rehydrated in descending ethanol series $(100 \%$ twice for $3 \mathrm{~min}$; $95 \%$ for 

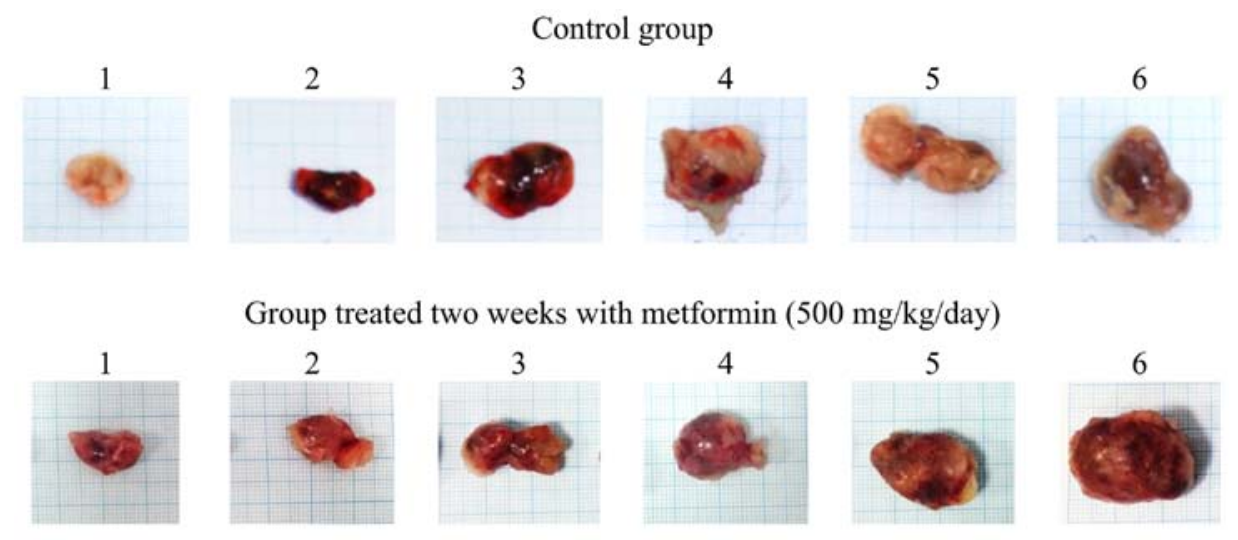

Group treated two weeks with metformin $(500 \mathrm{mg} / \mathrm{kg} /$ day $)$
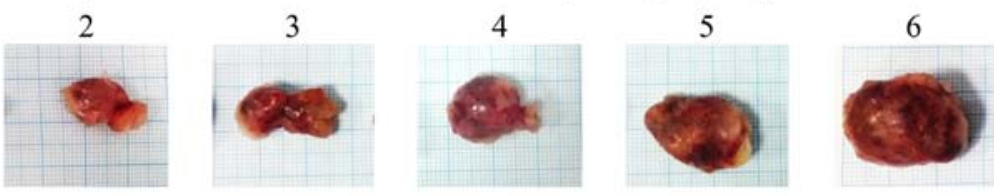

Group treated two weeks with itraconazole $(250 \mathrm{mg} / \mathrm{kg} / \mathrm{day})$
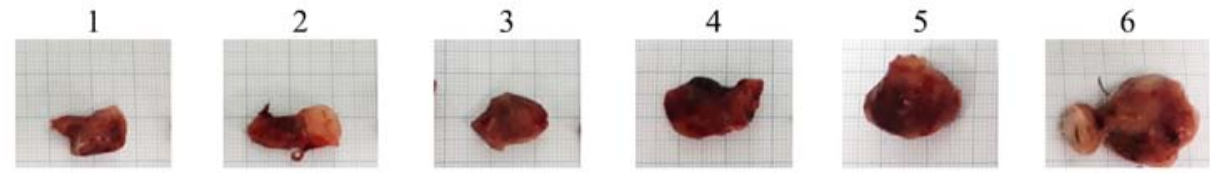

Group treated two weeks with the combination of metformin $(500 \mathrm{mg} / \mathrm{kg} /$ day $)$ and itraconazole $(250 \mathrm{mg} / \mathrm{kg} /$ day $)$
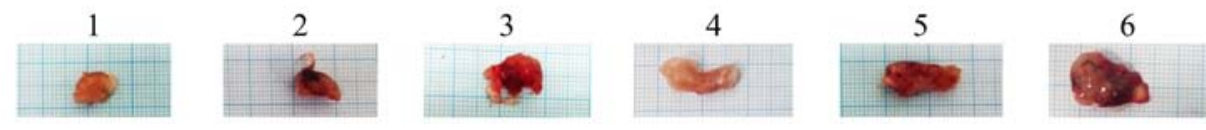

Figure 1. Excised fibrosarcoma tumors placed on 1-mm grid paper in ascending weight order for visual dimension comparison following 2-week treatment.
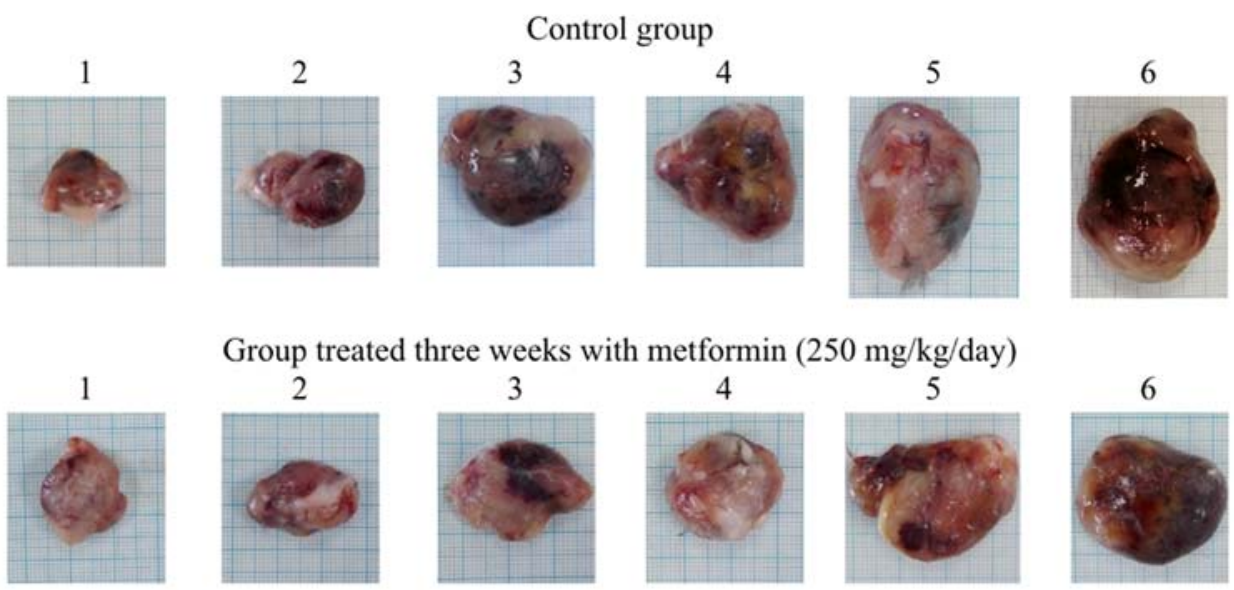

Group treated three weeks with metformin $(250 \mathrm{mg} / \mathrm{kg} /$ day $)$
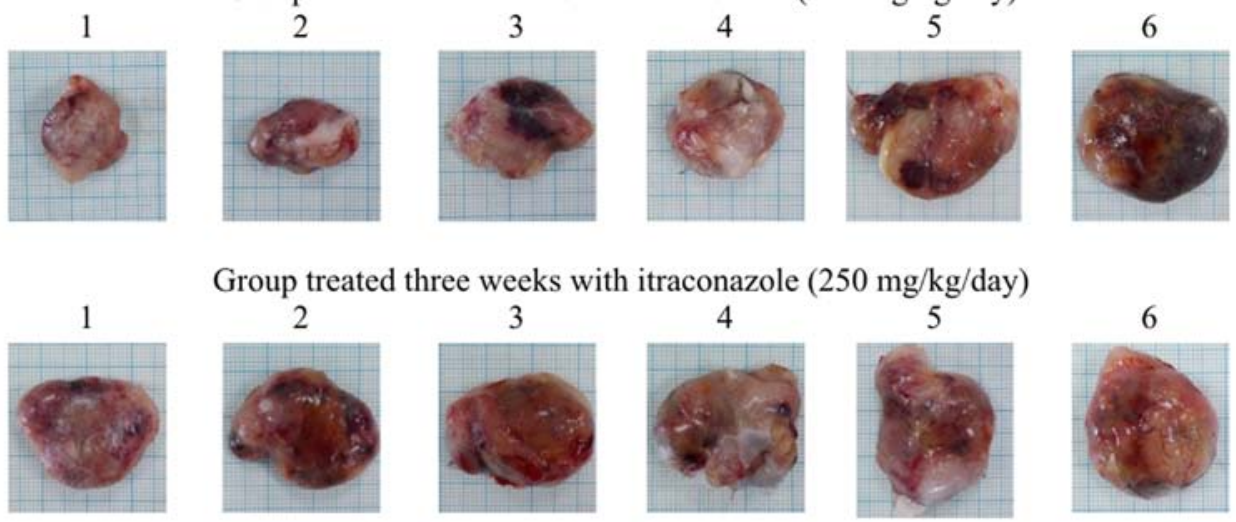

Group treated three weeks with the combination of metformin $(250 \mathrm{mg} / \mathrm{kg} / \mathrm{day})$ and itraconazole $(250 \mathrm{mg} / \mathrm{kg} /$ day $)$
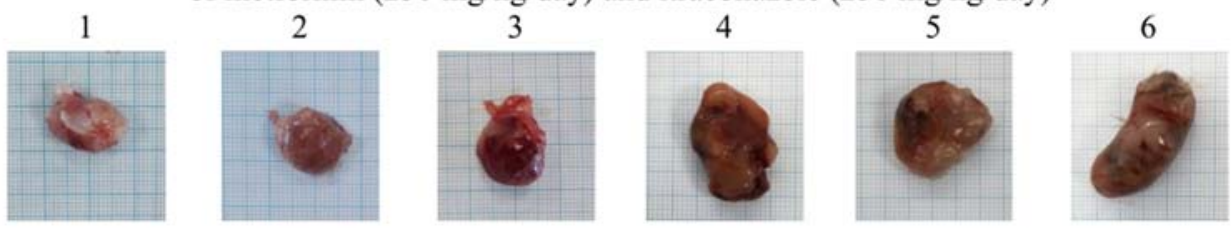

Figure 2. Excised fibrosarcoma tumors placed on 1-mm grid paper in ascending weight order for visual dimension comparison after 3-week treatment. 
After two-week treatment
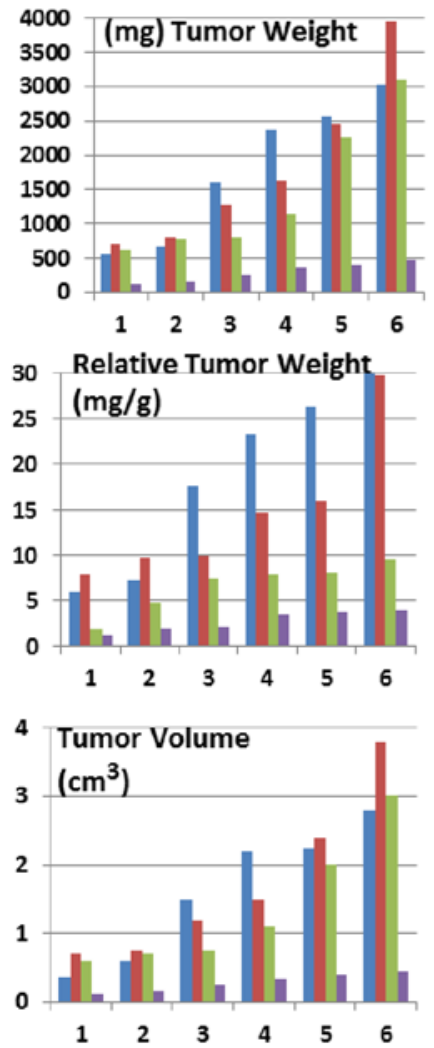

1.12 Tumor Density $\left(\mathrm{mg} / \mathrm{mm}^{3}\right)$

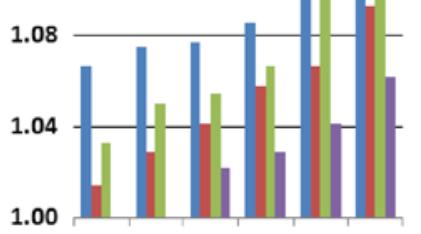

$\begin{array}{llllll}1 & 2 & 3 & 4 & 5 & 6\end{array}$

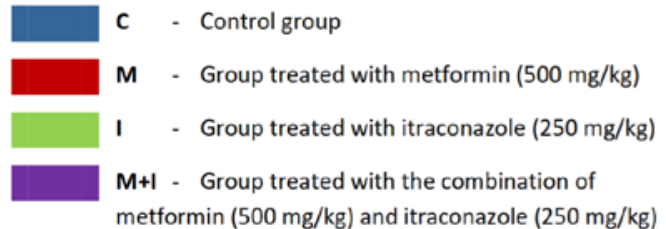

Mean +/-SD (mg/g)

C $M \quad \mathrm{M}+\mathrm{I}$
After three-week treatment
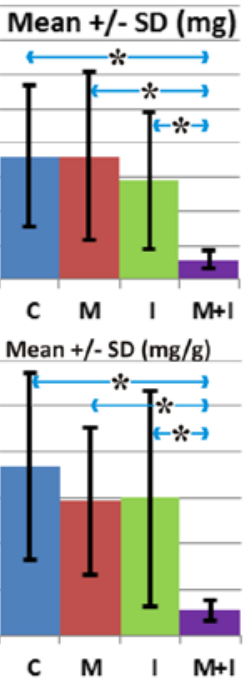

Mean $+/-$ SD $\left(\mathrm{cm}^{3}\right)$

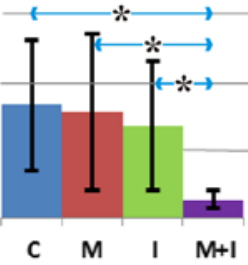

Mean $+/$ - SD $\left(\mathrm{mg} / \mathrm{mm}^{3}\right)$
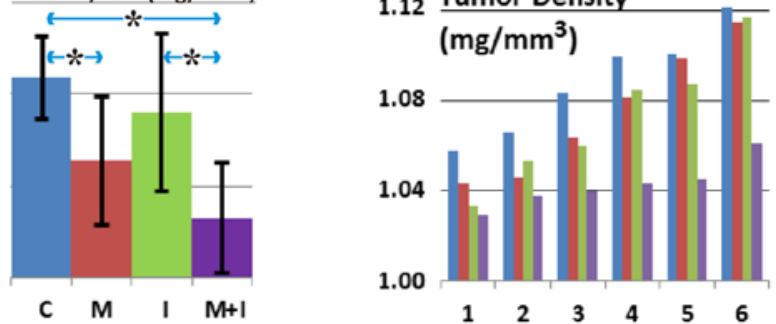

Mean +/- SD (mg)
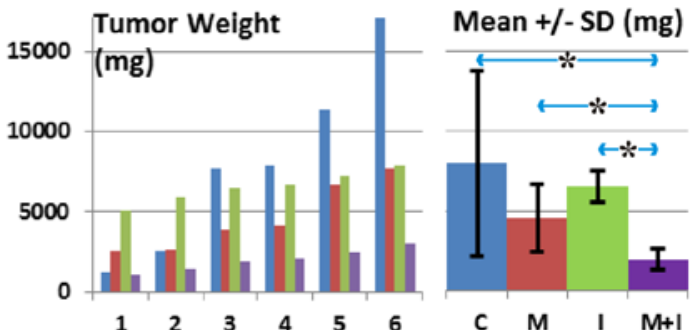

C $\quad \mathrm{M} / \mathrm{M}+\mathrm{I}$

100 Relative Tumor Weight
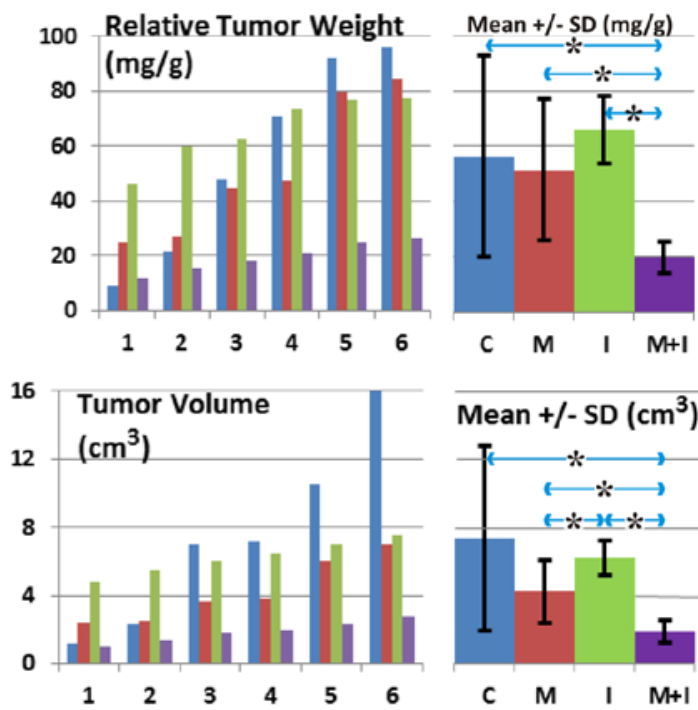

Mean $+/-$ SD $\left(\mathrm{cm}^{3}\right)$

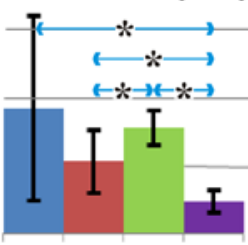

C $\mathrm{M}, \mathrm{M}+\mathrm{I}$
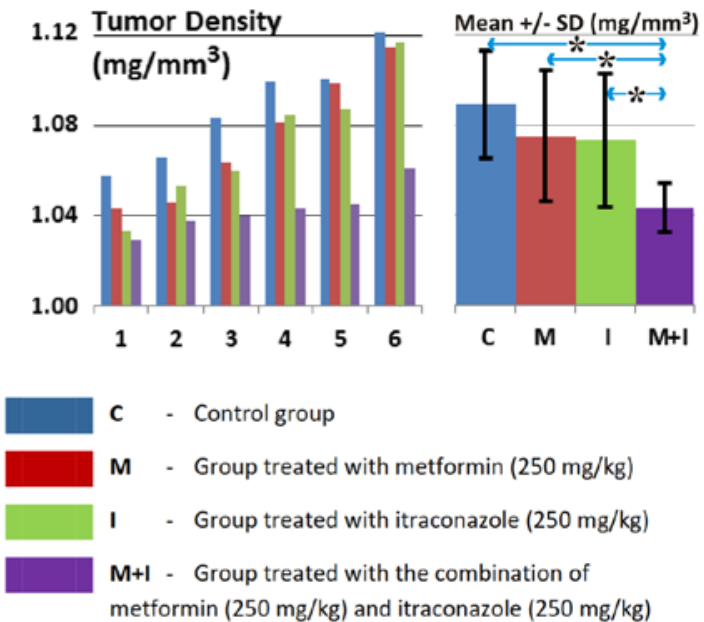

Figure 3. Characteristics of the excised tumors. Tumor weight, relative weight, volume and density, among the treated groups of animals. " $\mathrm{P}<0.05$, as indicated.

$3 \mathrm{~min}$ and $70 \%$ for $3 \mathrm{~min})$. For antigen retrieval, the sections were microwaved $\left(850 \mathrm{~W} ; \sim 98^{\circ} \mathrm{C}\right)$ for $20 \mathrm{~min}$ in Tris-EDTA buffer $[10 \mathrm{mM}$ Tris Base, $1 \mathrm{mM}$ EDTA solution, $0.05 \%$ Tween 20 (pH 9.0)], washed twice for 5 min with TBS plus $0.025 \%$ Triton X-100 (with agitation) and blocked by immersion in $10 \%$ goat serum (cat. no. G6767; Sigma-Aldrich; Merck $\mathrm{KGaA}$ ) in TBS with 1\% BSA (cat. no. T6789; Sigma-Aldrich; Merck KGaA) for $2 \mathrm{~h}$ at room temperature. Primary antibodies dissolved in TBS with $1 \%$ BSA were incubated at $4^{\circ} \mathrm{C}$ overnight. The sections were washed twice for 5 min with TBS plus $0.025 \%$ Triton X-100 (with agitation) and incubated with $0.3 \%$ $\mathrm{H}_{2} \mathrm{O}_{2}$ in TBS for $15 \mathrm{~min}$ at room temperature. Horseradish peroxidase-conjugated goat polyclonal rabbit immunoglobulin G secondary antibody (cat. no. ab6721; Abcam) dissolved in TBS with $1 \%$ BSA was added to the sections for $2 \mathrm{~h}$ at room temperature. The sections were washed three times for $5 \mathrm{~min}$ with TBS. For visualization, the chromogen 3,3-diaminobenzidine tetrahydrochloride (cat. no. K3468; Liquid DAB + SubstratChromogen System; Dako; Agilent Technologies, Inc.) was added and incubated for $10 \mathrm{~min}$ at room temperature. The sections were washed with water for $5 \mathrm{~min}$ and stained with Mayer's hematoxylin for $5 \mathrm{~min}$ at room temperature. The stained tumor slices were assessed using Leica DMLB 100T (Leica Microsystems GmbH) microscope at x400 magnification. Images were captured using a Leica MC190 HD camera (Leica Microsystems GmbH). The images of Ki-67 staining were processed using the UTHSCSA Image Tool for Windows version 3.00 (32). In each sample image, 
After two-week treatment

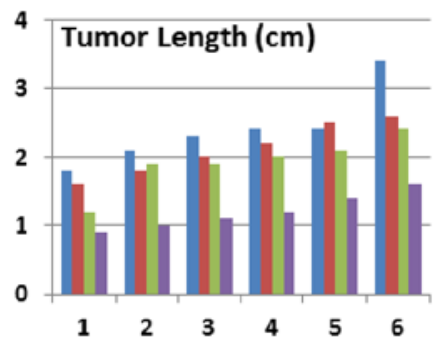

Mean +/-SD (cm)
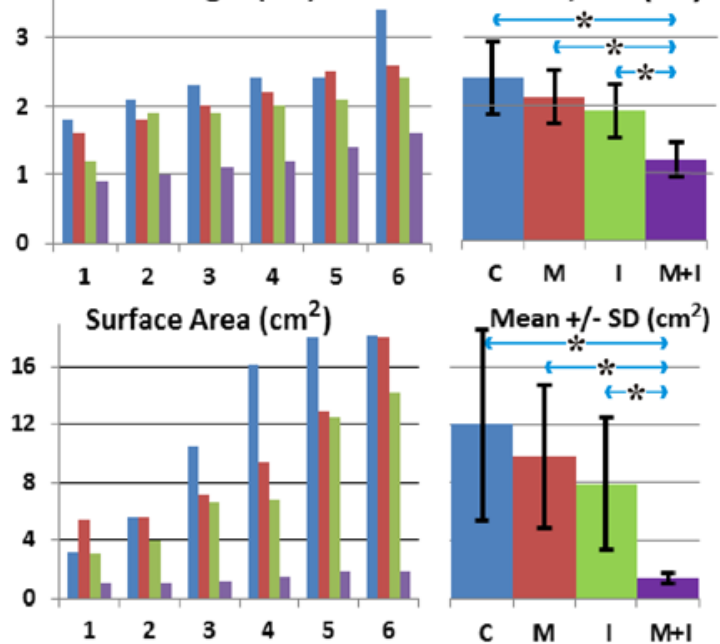

10 Surface/Volume $\left(\mathrm{cm}^{-1}\right)$
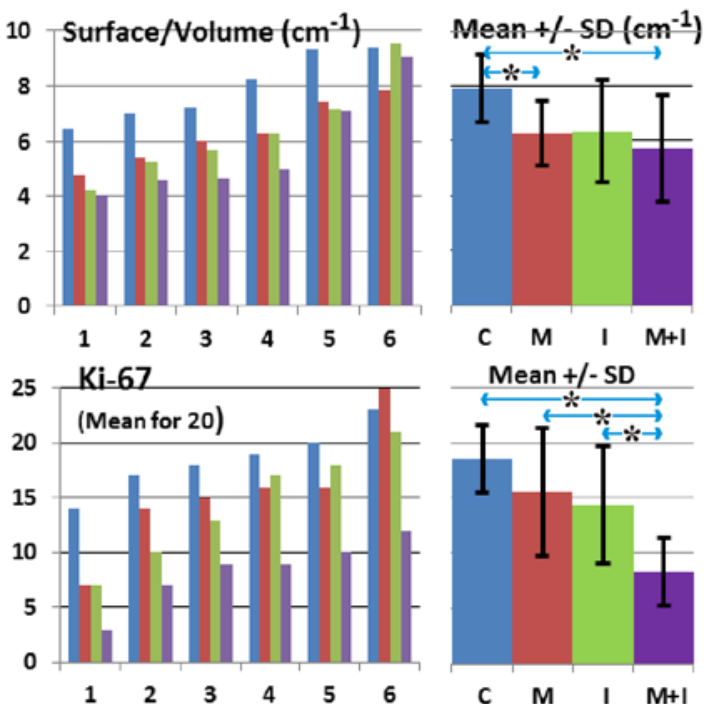

C - Control group

M - Group treated with metformin $(500 \mathrm{mg} / \mathrm{kg})$

I - Group treated with itraconazole $(250 \mathrm{mg} / \mathrm{kg})$

M+1 - Group treated with the combination of metformin $(500 \mathrm{mg} / \mathrm{kg})$ and itraconazole $(250 \mathrm{mg} / \mathrm{kg})$
After three-week treatment
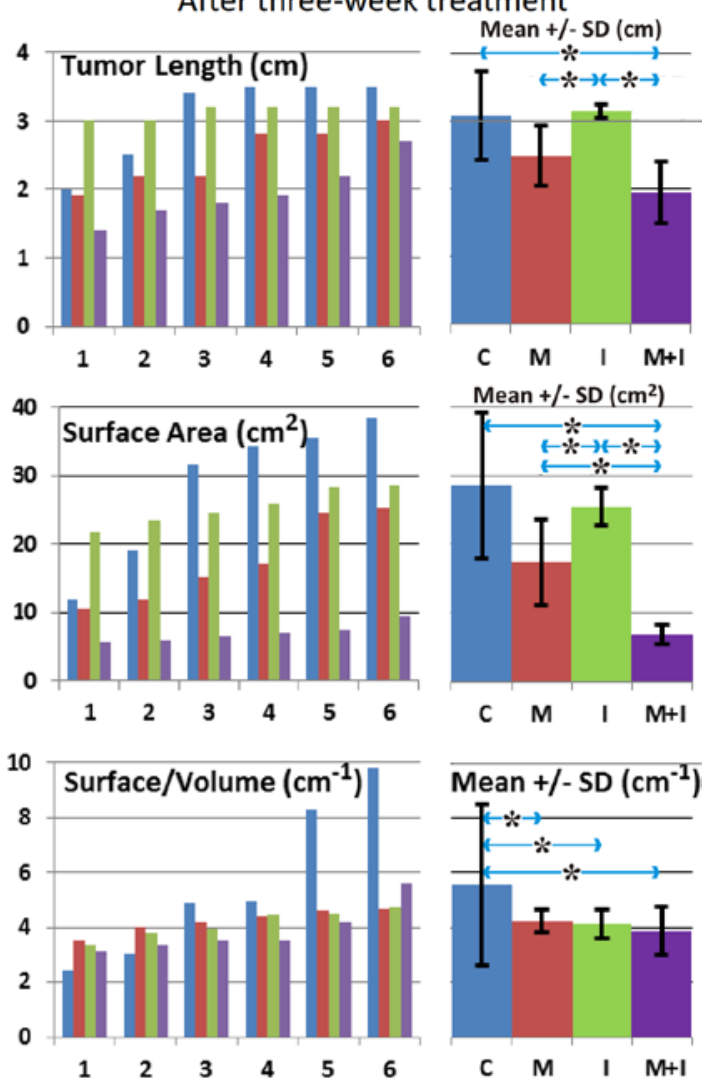

Mean +/-SD $\left(\mathrm{cm}^{-1}\right)$

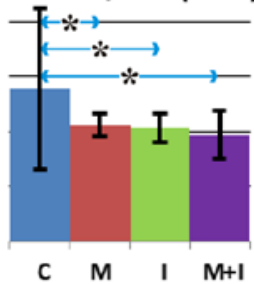

Mean + /-SD
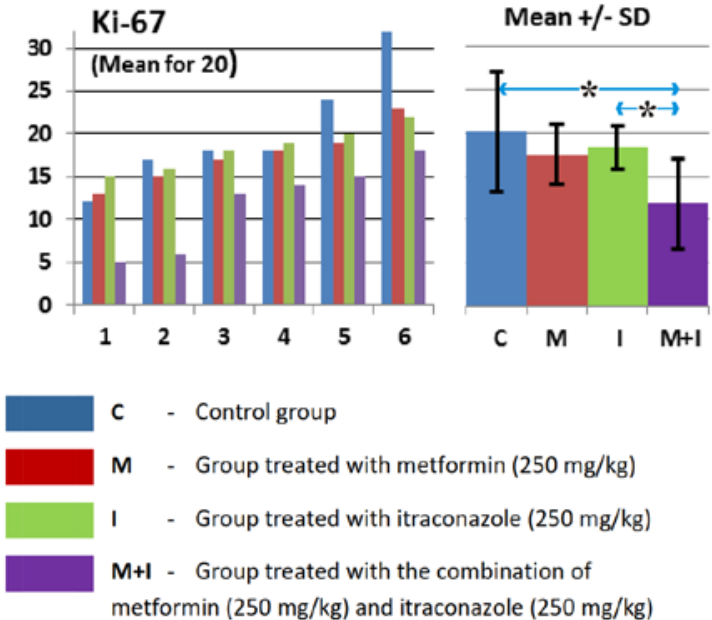

Figure 4. Characteristics of the excised tumors. Tumor length, surface area, surface/volume ratio and Ki-67 positivity, among the treated groups of animals. ${ }^{*} \mathrm{P}<0.05$, as indicated.

the number of Ki-67-positive cells was counted. The mean numbers of Ki-67-positive cells in 20 tumor images from each animal were compared among the groups.

CD34, COX4, GLUT1 and iNOS staining was used to evaluate the vasculature, apoptosis, glucose metabolism and NO production in the tumor specimens, respectively. Immunoexpression was evaluated based on the measured portion of stained surface area (stained surface/whole surface) in the tumor sections (mean of 10 measurements) using UTHSCSA Image Tools for Windows version 3.00.

In vitro antiproliferative assay. The tested treatments were evaluated for their in vitro antiproliferative effects in hamster fibrosarcoma BHK-21/C13, human cervical carcinoma HeLa (CCL-2), colon carcinoma HT-29 (HTB-38), lung carcinoma A549 (CCL-185) and normal fetal lung MRC-5 (CCL-171) cells. All cell lines were obtained from the American Type Culture Collection. The cell lines were authenticated and mycoplasma testing was conducted. The cell lines were cultured in DMEM with $4.5 \mathrm{~g} / 1$ glucose containing $10 \%$ FBS and $1 \%$ penicillin-streptomycin in an incubator at $37^{\circ} \mathrm{C}$ with $5 \% \mathrm{CO}_{2}$. A standard MTT assay (33) was performed to evaluate the cytotoxic effects of the treatments following exposure to doses of $50,100,250,350,500 \mu \mathrm{M}$ and $1,2,3,4,5,10$, $20,50 \mathrm{mM}$ at $37^{\circ} \mathrm{C}$ for $48 \mathrm{~h}$. The antiproliferative effect was expressed as the half maximal inhibitory concentration $\left(\mathrm{IC}_{50}\right)$. 


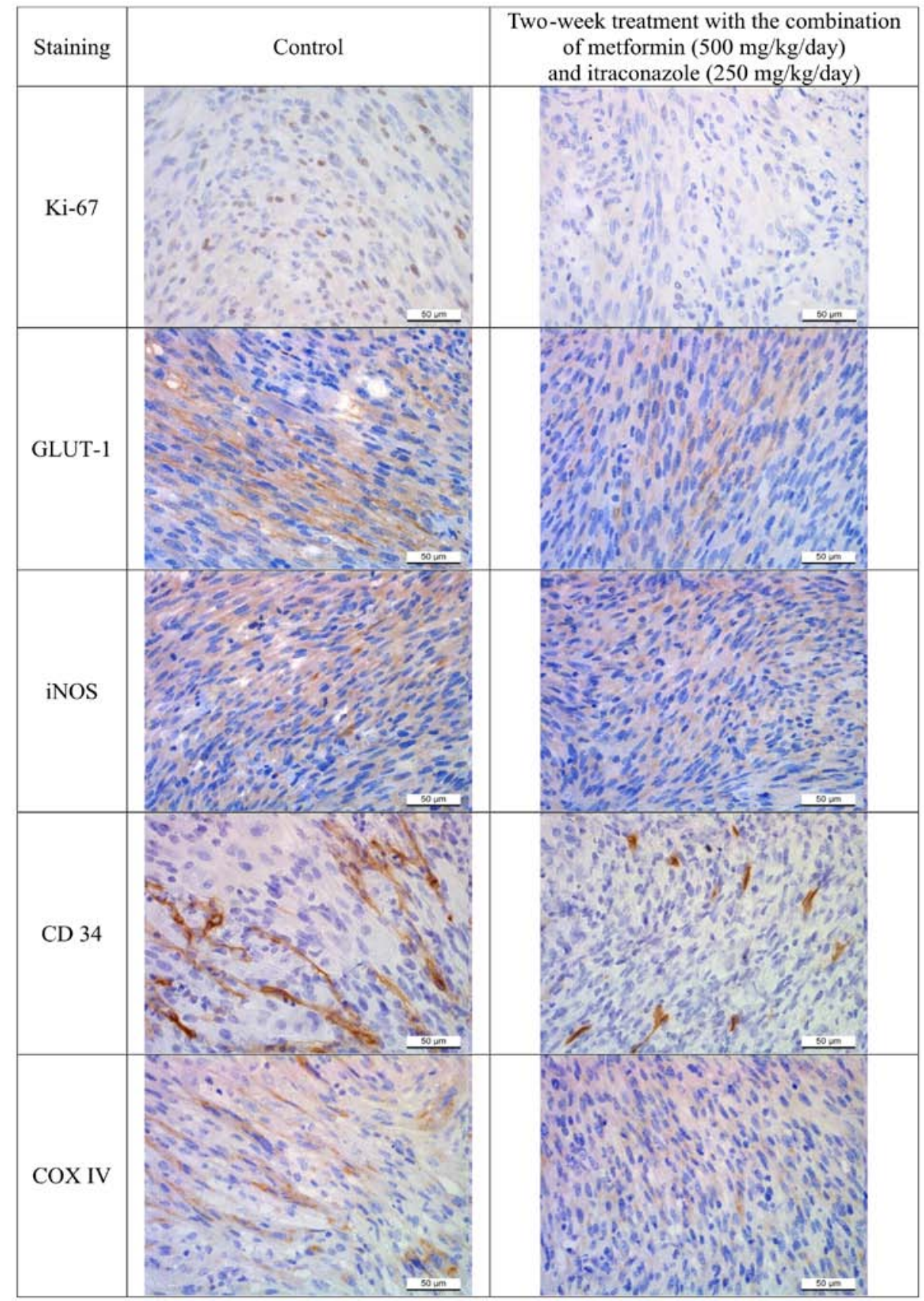

Figure 5. Inhibition of tumor growth and vasculature by metformin and itraconazole. Marked decreases were observed in the immunohistochemical staining of Ki-67, GLUT1, iNOS, CD34 and COX4 in the group treated with the combination of metformin and itraconazole compared with the control group. COX4, cytochrome $c$ oxidase subunit 4; GLUT1, glucose transporter 1; iNOS, inducible nitric oxide synthase.

Blood biochemical tests. Blood samples were collected from the hamsters for blood measurements, including glucose, erythrocytes, leucocytes, lymphocytes, monocytes, granulocytes, platelets, hemoglobin, hematocrit, mean corpuscular volume, mean corpuscular hemoglobin, mean corpuscular hemoglobin concentration, serum proteins, albumins and sedimentation. Full blood cell counts were obtained using an auto hematology analyzer (Abacus Junior Vet; Diatron; Stratec SE). The serum, extracted by centrifugation at 2,000 $\mathrm{x} g$ for $10 \mathrm{~min}$ from the blood samples, was analyzed using an auto chemistry analyzer (Rayto Life and Analytical Sciences Co., Ltd.) and by commercial tests for concentration determination of glucose (cat. no. 21503), serum proteins (cat. no. 11500) and albumins (cat. no. 11547; BioSystems S.A.).
Statistical analysis. The data are presented as means \pm standard deviations. The differences among the groups in tumor weight, volume, density, length, surface area, S/V ratio, mean number of Ki-67-positive cells and other measured parameters were determined using one-way ANOVA followed by a Student-Newman-Keuls post hoc test. Data analysis was conducted using TIBCO Statistica 13.3.1 software (TIBCO Software, Inc.). $\mathrm{P}<0.05$ was considered to indicate a statistically significant difference.

\section{Results}

Co-treatment with metformin and itraconazole has antitumor effects in a hamster fibrosarcoma model. The subcutaneous 

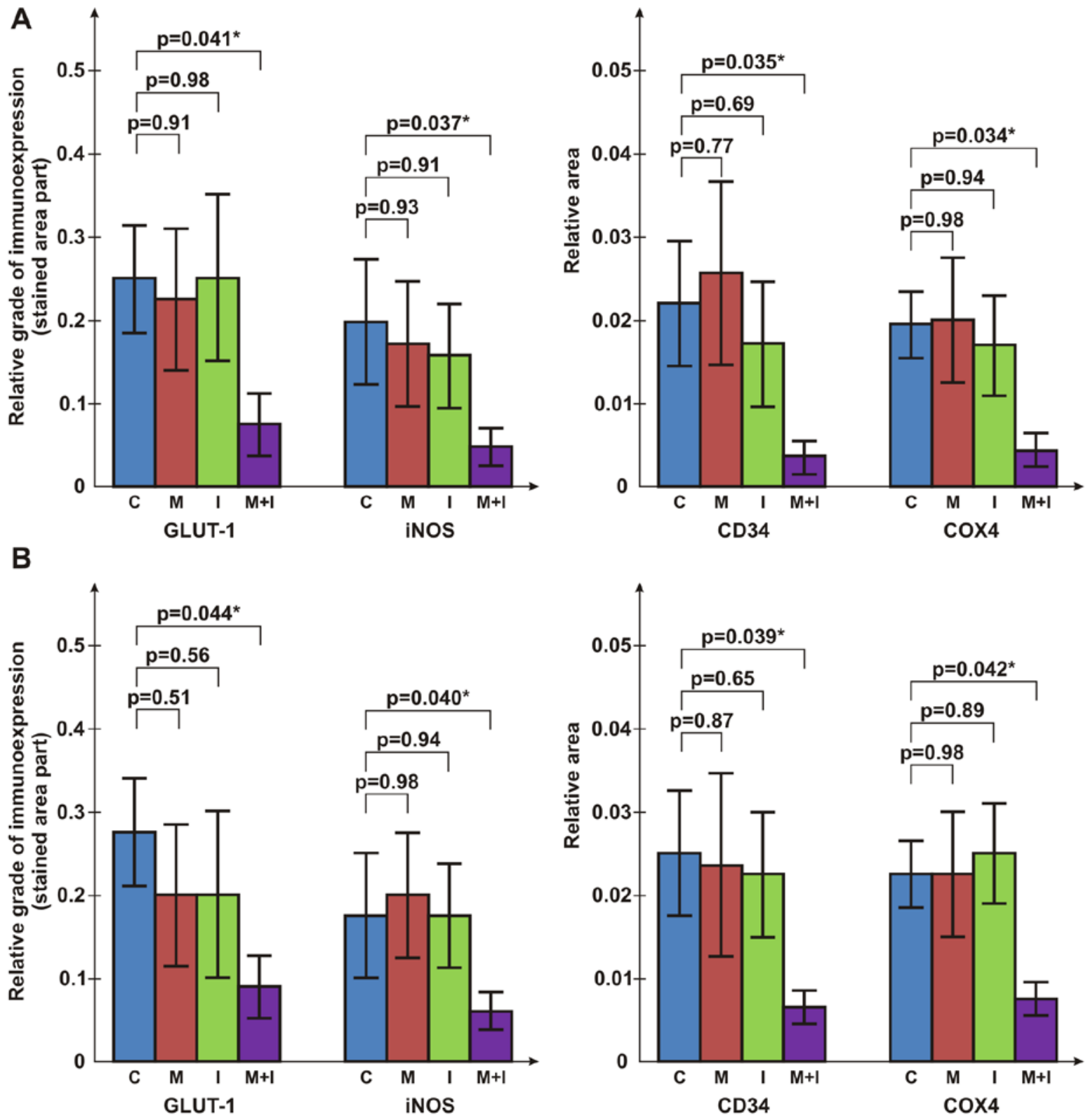

Figure 6. Extent of immunoexpression of GLUT1, iNOS, CD34 and COX4. Mean stained area in the groups treated for (A) 2 and (B) 3 weeks. "P<0.05. (C) control group; COX4, cytochrome $c$ oxidase subunit 4; GLUT1, glucose transporter 1; I, group treated with itraconazole; iNOS, inducible nitric oxide synthase; M, group treated with metformin; M+I, group treated with the metformin/itraconazole combination.

inoculation of BHK-21/C13 cells into hamsters (Table I) resulted in fibrosarcoma formation at the site of injection in all inoculated animals. All experimental animals had isolated, well-demarcated solid tumors without adverse effects on general health and well-being. Pathological and histopathological analysis following autopsy revealed no signs of metastases or ascites. Perioral co-treatment with metformin and itraconazole significantly inhibited tumor growth at 2 and 3 weeks, as indicated by significant decreases in tumor weight, relative weight, volume, density, length, surface area and $\mathrm{S} / \mathrm{V}$ ratio, as well as by the decreased proliferation status of tumor cells, as demonstrated by Ki-67 staining of the hamster tumor sections at 2 and 3 weeks (Tables II and III; Figs. 1-4). Notably, following a 3-day pre-treatment, only the combination of metformin and itraconazole resulted in a statistically significant antitumor effect compared with control (Tables II and III).
The pathohistological and immunohistochemical evaluation revealed a decrease in tissue penetration, an expansion of necrosis and hemorrhagic areas, inhibition of tumor growth and vasculature in all analyzed slices of tumors from animals treated with the combination of metformin and itraconazole compared with the control group (Figs. 5 and 6). The combined metformin and itraconazole therapy exhibited tumor cytotoxicity between the early and late tumor treatment stages (days 14-21 post tumor inoculation; Tables II and III; Figs. 3, 4 and 6).

The treatments had no significant effect on the body weight of the hamsters during the course of the study (Table I).

Treatment with metformin alone resulted in a nonsignificant $(\mathrm{P}>0.05)$ decrease in the fasting blood glucose levels in the hamsters (Tables IV and V). Additionally, the experimental and control groups were statistically compared for 


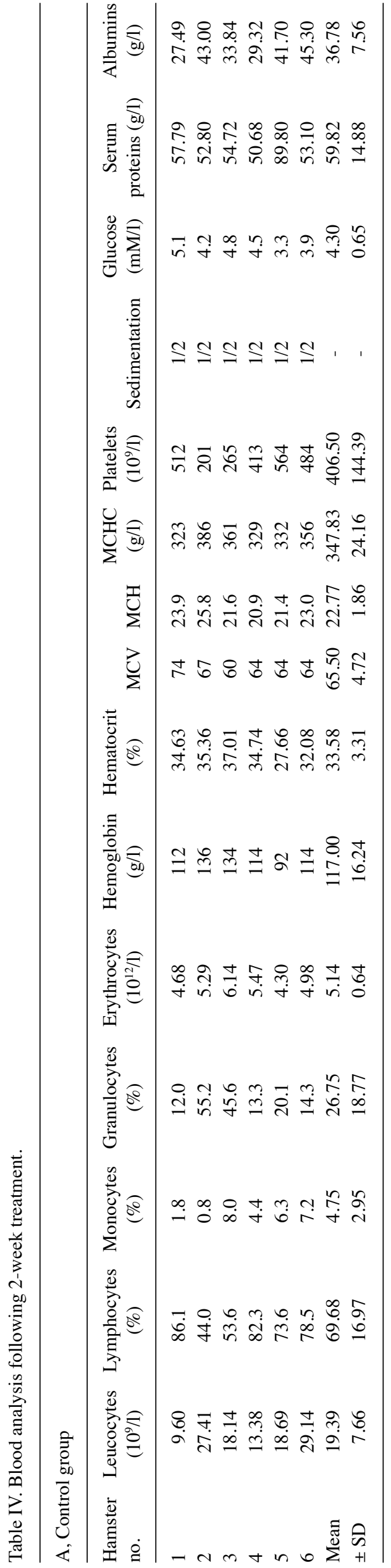

\begin{tabular}{|c|c|}
\hline 急 $\widehat{\overline{0}}$ & 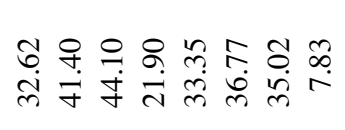 \\
\hline 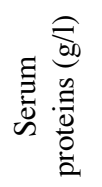 & 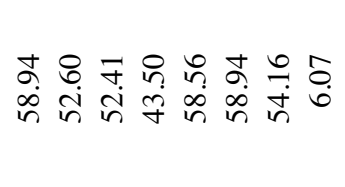 \\
\hline 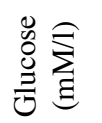 & 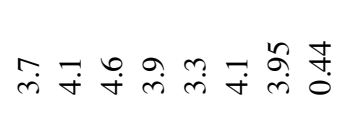 \\
\hline 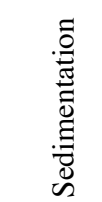 & 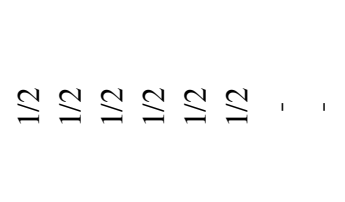 \\
\hline 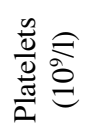 & 我品 \\
\hline 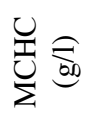 & 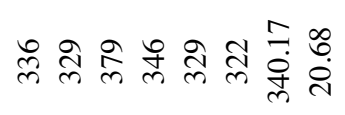 \\
\hline$\underset{\Sigma}{\mathbb{E}}$ & 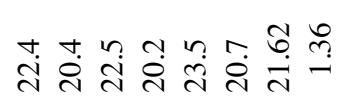 \\
\hline Z & ธலర ڤิ \\
\hline 胥 & 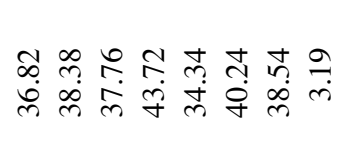 \\
\hline 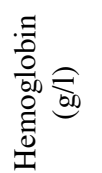 & 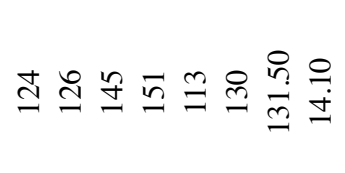 \\
\hline 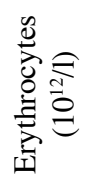 & त̂ \\
\hline 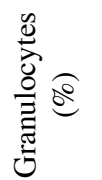 & 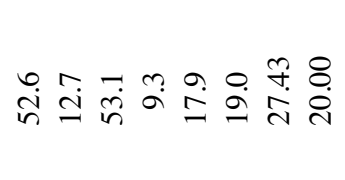 \\
\hline 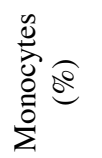 & 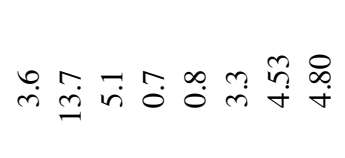 \\
\hline 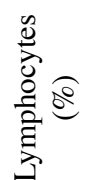 & 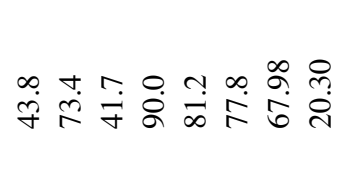 \\
\hline 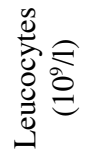 & 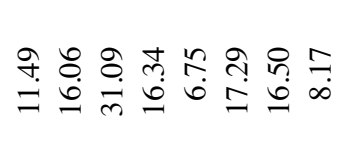 \\
\hline$E$ & ङ \\
\hline
\end{tabular}

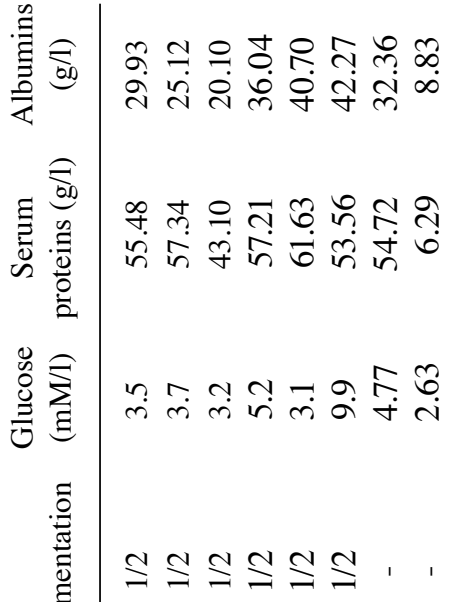

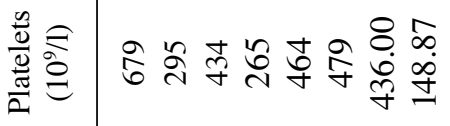

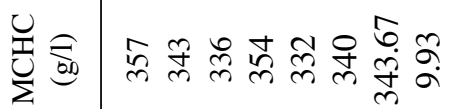

चี

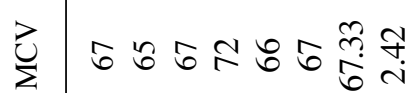

若

离

लं

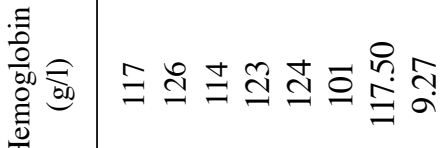

I

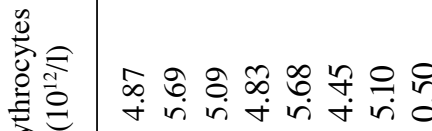

产

离

鿒

产

$\sum_{\Sigma}^{\circ}$

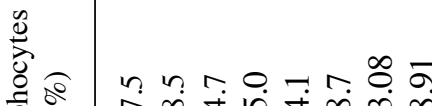

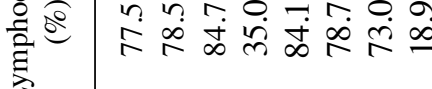
实

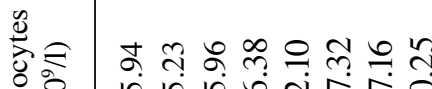

过的的过

离 
red and white blood cell counts, platelet number, hemoglobin levels, hematocrit levels, serum proteins and sedimentation, but no significant differences were observed among the groups ( $\mathrm{P}>0.05)$. In addition, examination of the vital organs revealed no pathological or toxicological differences between the experimental and control groups.

Co-treatment with metformin and itraconazole has antiproliferative effects in cancer cell lines. The antiproliferative effects in fibrosarcoma, carcinoma and normal cell lines, expressed as $\mathrm{IC}_{50}$, for all treatments are presented in Table VI. Co-treatment with metformin and itraconazole exhibited selective cytotoxicity against the malignant cell lines (HeLa, HT-29, A549 and BHK-21/C13). The combination demonstrated favorable antiproliferative effects in the normal fetal lung MRC-5 cells, suggesting that this treatment may be safe and efficient.

\section{Discussion}

A number of common or separate anticancer mechanisms of metformin (3) and itraconazole (11) have been identified. Among the potential anticancer targets of these drugs, AMPK/mTOR inhibition, anti-angiogenesis, and folate and autophagy inhibition are notable common functions. The chemosensitization properties of itraconazole (34) are also important, since they enhance the therapeutic efficacy of anticancer drugs through the inhibition of P-gp.

The combination of metformin and itraconazole in the present study resulted in reductions in fibrosarcoma tumor weight, relative weight, volume, density, length, surface area, $\mathrm{S} / \mathrm{V}$ ratio, proliferation, vasculature and tissue penetration. These effects, as well as increased tumor necrosis and hemorrhage observed in the immunohistochemical and histological evaluation, may be due to the cytotoxicity of the treatment, which may alter the expression of proteins that regulate the proliferation and apoptosis of tumor cells, and vascular growth (35). The radiologically determined (4-dimension computed tomography) density of non-small cell lung cancer tumors has been reported to vary between 0.236 and $1.010 \mathrm{~g} / \mathrm{cm}^{3}$ (36). Denser tumors are more likely to have poorer outcomes and result in shorter disease-free survival times (36). The $\mathrm{Ki}-67$ protein is a cellular marker for proliferation, present during all active phases of the cell cycle $\left(G_{1}, S, G_{2}\right.$ and $\left.M\right)$, and absent in the resting phase. The Ki-67 antigen can be exclusively detected within the cell nucleus. GLUT1 facilitates the transport of glucose across membranes and is overexpressed in cancer (3). Increased glycolysis, with increased expression of GLUT1, is associated with poor cancer prognosis. Increased iNOS immunostaining in the cytoplasm denotes tumor progression by increasing proliferation and angiogenesis (11), which is associated with poor outcome in various types of cancer. CD34 is a marker of endothelial cells and vascular differentiation (11). COX4 is a mitochondrial cytochrome $c$ oxidase marker overexpressed in cancer cells (14).

In a previous study, the metformin levels in the colorectal cancer cells of xenograft-bearing mice that were successfully treated orally and intraperitoneally corresponded to the plasma concentrations (37). This indicates a consistent delivery of the drug to the tumor tissue. In the present study, the same orders 


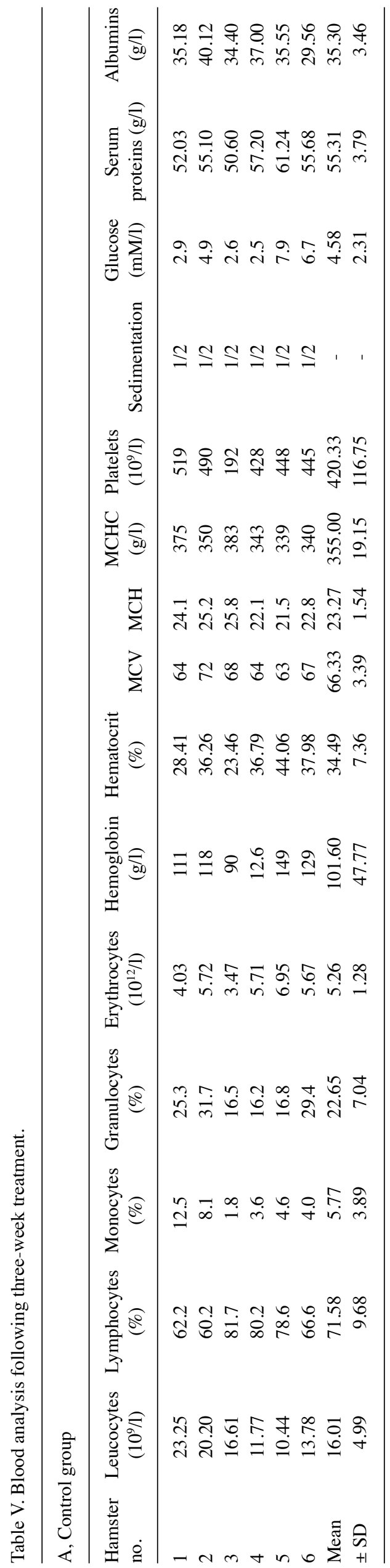

\begin{tabular}{|c|c|}
\hline 言 & 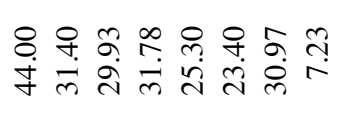 \\
\hline 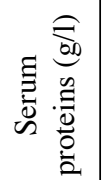 & 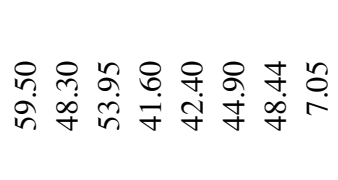 \\
\hline 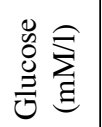 & 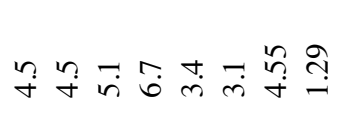 \\
\hline 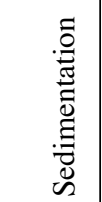 & $\stackrel{N}{S} \mathbb{S} S \mathbb{S}$ \\
\hline 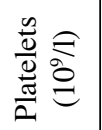 & 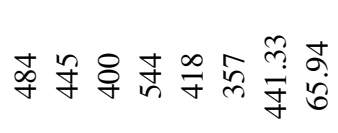 \\
\hline 壱 & 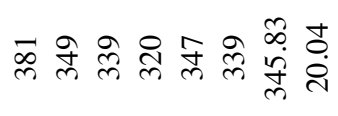 \\
\hline $\mathbb{U}_{\Sigma}^{\mathbb{Z}}$ & 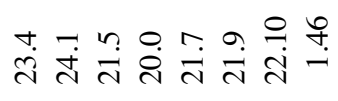 \\
\hline$Z_{\Sigma}^{Z}$ & б \\
\hline 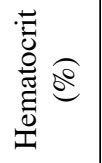 & 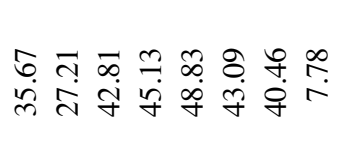 \\
\hline 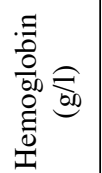 & 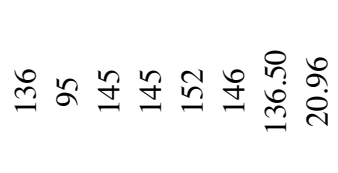 \\
\hline 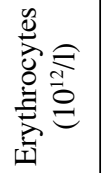 & 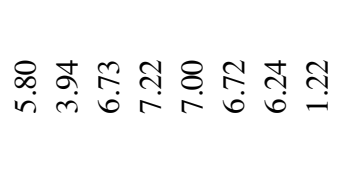 \\
\hline 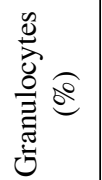 & 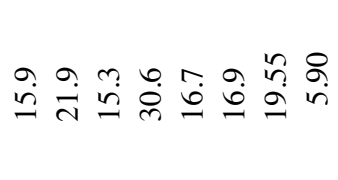 \\
\hline 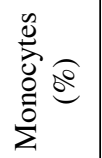 & 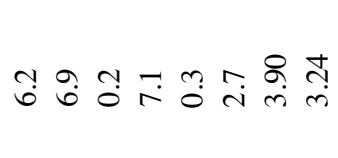 \\
\hline 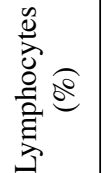 & 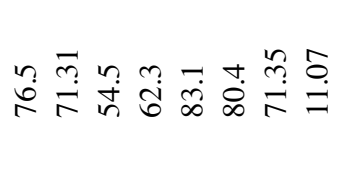 \\
\hline 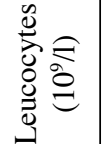 & 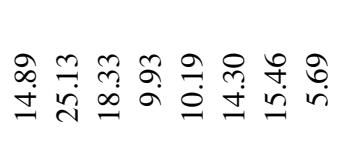 \\
\hline 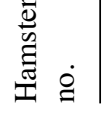 & 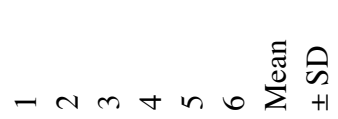 \\
\hline
\end{tabular}

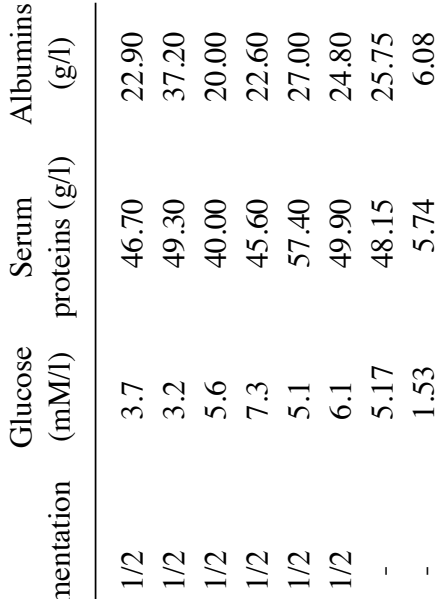

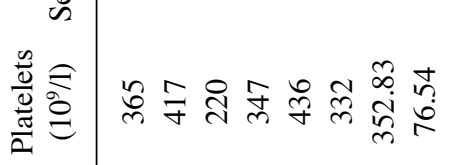

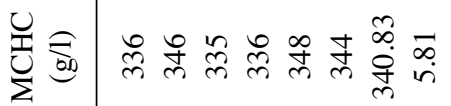

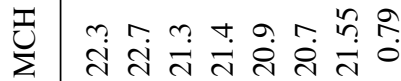

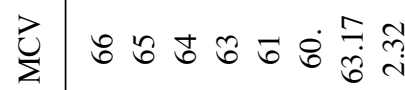

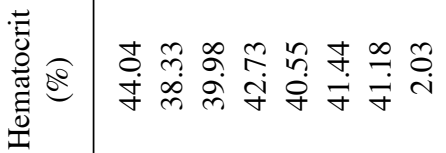

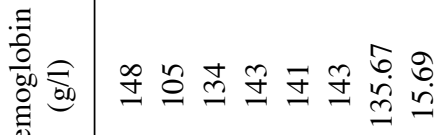

폰

豙

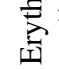

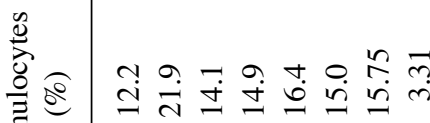

药

矛

$\sum$

管 空

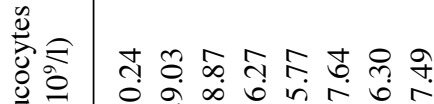
过

岕 

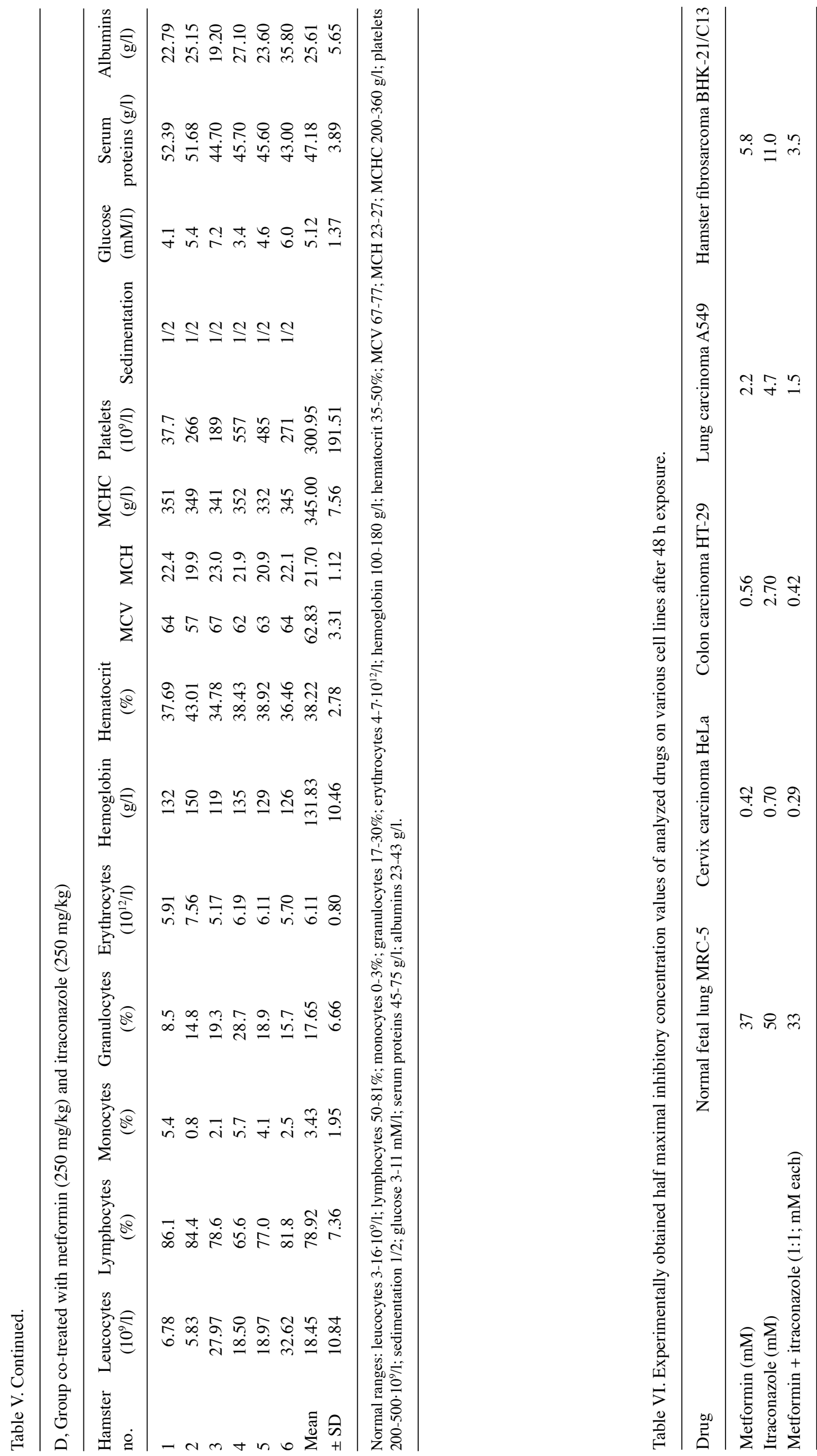
of magnitude of oral metformin doses were administered to the hamsters, compared with the doses administered in a previous study (37). For the 2-week treatment, metformin and itraconazole doses of $\sim 30 \%$ of the median lethal dose $\left(\mathrm{LD}_{50}\right)$ for this species were selected; as metformin $\mathrm{LD}_{50}$ is $1,450,500 \mathrm{mg} / \mathrm{kg}$ was used. The daily dose of $500 \mathrm{mg} / \mathrm{kg}$ metformin in hamsters is equivalent to the maximum daily dose of $40 \mathrm{mg} / \mathrm{kg}$ in patients with diabetes normalized to body surface (38). The dosage of $500 \mathrm{mg} / \mathrm{kg} /$ day metformin used in 2-week treatment was twice higher compared with the equivalent of the $20 \mathrm{mg} / \mathrm{kg} /$ day typically administered to patients with diabetes. Therefore, a lower dose of metformin $(250 \mathrm{mg} / \mathrm{kg})$ was selected for the 3 -week treatment to prevent possible toxicity induced by prolonged application of the maximal dose.

During the 2- and 3-week treatments, tumor diameters reached $\sim 2.5$ and $3.5 \mathrm{~cm}$ in the untreated control groups, respectively. Since the metformin doses in the 2- and 3-week treatment groups were different, the effects of the treatments were evaluated separately for each treatment period. The 3 -week treatment results confirmed and validated the results of the 2-week treatment, which demonstrated the significant anticancer effects of the co-treatment on hamster fibrosarcoma.

Itraconazole treatment has been reported to suppress the growth of medulloblastoma and basal cell carcinoma in a mouse allograft model at serum concentrations comparable to those in patients undergoing antifungal therapy (39). The itraconazole levels achieved in the tumors were similar to those in serum, indicating that itraconazole exhibits good tumor tissue penetration (39). The human daily dose of $20 \mathrm{mg} / \mathrm{kg}$ itraconazole is equivalent to a daily dose of $250 \mathrm{mg} / \mathrm{kg}$ in hamsters normalized to body surface (38). In previous studies, the anti-angiogenic effect of itraconazole was reported to function synergistically in combination with the effects of classical toxic chemotherapeutic drugs, such as paclitaxel, in epithelial ovarian (40) and non-small cell lung carcinoma (41) xenograft mouse models.

The anticancer properties of the present metformin and itraconazole co-treatment doses in hamsters, and the possibility of achieving comparably high nontoxic levels in humans, suggest that the prospect of effective nontoxic oncological therapy and prevention of cancer relapse using this drug combination may be achievable. The present in vitro results from normal and malignant cell lines (MRC-5, BHK-21/C13, HeLa, HT-29 and A549) supported the in vivo findings from the hamster fibrosarcoma tumors. In addition, in other studies, metformin (42) and itraconazole (11) separately inhibit tumor cell migration and invasion in vitro. Furthermore, metformin alone inhibits invasion and migration of human fibrosarcoma cells (42). Therefore, metformin may have the potential to prevent fibrosarcoma metastasis. Itraconazole alone inhibits the proliferation of cancer-associated fibroblasts, serving a key role in cell proliferation, invasion and metastasis in cancer (11). Therefore, the effects of co-treatment with metformin and itraconazole on the migration and invasion of fibrosarcoma cells need to be studied further. Clinical trials are required to elucidate whether the combination of metformin and itraconazole has the potential to become an adjuvant or relapse prevention treatment in current anticancer and particularly antisarcoma therapies.
In conclusion, nontoxic oral doses of metformin combined with nontoxic doses of itraconazole significantly inhibited sarcoma growth in hamsters and exhibited anticancer properties in various cancer cell lines; this combination may be a candidate for novel safe anticancer adjuvant or relapse prevention therapy.

\section{Acknowledgements}

The authors would like to thank Mrs. Vesna Popović (Department for Technical and Administrative Services of Provincial Authorities, Provincial Government, Autonomous Province of Vojvodina) for her expert technical assistance and suggestions during the preparation of this study.

\section{Funding}

This study was supported by the Republic of Serbia, Autonomous Province of Vojvodina, Provincial Secretariat for High Education and Scientific Research [grant no. 142-451-2413/2018 (JP)] and Republic of Serbia, Ministry of Science [grant nos. 171039 (JS) and 172013 (DM)].

\section{Availability of data and materials}

The datasets used and/or analyzed during the current study are available from the corresponding author on reasonable request.

\section{Authors' contributions}

KJP made substantial contributions to the conception and design of the investigation, and performed physical biometrical analyses of the hamster tumors. DJP was a major contributor in writing the manuscript and in performing the blood analyses. DM performed the randomization, tumor inoculation and treatment of hamsters. DL performed the histological and toxicological analyses. IC performed the immunohistochemical analyses. JKP made substantial contribution to the statistical analysis and interpretation of all experimental data. All authors read and approved the final version of the manuscript.

\section{Ethics approval and consent to participate}

The study was approved by the Ethics Committee of the University of Novi Sad (approval no. 01-78/18-5; dated April 26, 2016).

\section{Patient consent for publication}

Not applicable.

\section{Competing interests}

The authors declare that they have no competing interests.

\section{References}

1. Park SY, Kim D and Kee SH: Metformin-activated AMPK regulates $\beta$-catenin to reduce cell proliferation in colon carcinoma RKO cells. Oncol Lett 17: 2695-2702, 2019. 
2. Zi F,Zi H,Li Y,He J, Shi Q and Cai Z: Metformin and cancer: An existing drug for cancer prevention and therapy. Oncol Lett 15: 683-690, 2018

3. Popović DJ, Lalošević D, Miljković D, Popović KJ, Čapo I and Popović JK: Effect of metformin on fibrosarcoma in hamsters. Eur Rev Med Pharmacol Sci 21: 5499-5505, 2017.

4. Meng XM, Ma XX, Tian YL, Jiang Q, Wang LL, Shi R, Ding L and Pang SG: Metformin improves the glucose and lipid metabolism via influencing the level of serum total bile acids in rats with streptozotocin-induced type 2 diabetes mellitus. Eur Rev Med Pharmacol Sci 21: 2232-2237, 2017.

5. Salis O, Bedir A, Ozdemir T, Okuyucu A and Alacam H: The relationship between anticancer effect of metformin and the transcriptional regulation of certain genes (CHOP, CAV-1, HO-1, SGK-1 and Par-4) on MCF-7 cell line. Eur Rev Med Pharmacol Sci 18: 1602-1609, 2014.

6. Purchiaroni F, Galli G and Annibale B: Metformin plus proton pump inhibitors therapy: The cobalamin deficiency challenge. Eur Rev Med Pharmacol Sci 19: 2501-2502, 2015.

7. Yang Y and Wu XH: Study on the influence of metformin on castration-resistant prostate cancer PC-3 cell line biological behavior by its inhibition on PLC $\varepsilon$ gene-mediated Notch1/Hes and androgen receptor signaling pathway. Eur Rev Med Pharmacol Sci 21: 1918-1923, 2017

8. Zhou HY, Zhu H, Yao XM, Qian JP, Yang J, Pan XD and Chen XD: Metformin regulates tight junction of intestinal epithelial cells via MLCK-MLC signaling pathway. Eur Rev Med Pharmacol Sci 21: 5239-5246, 2017.

9. Tan JS and Joseph WS: Common fungal infections of the feet in patients with diabetes mellitus. Drugs Aging 21: 101-112, 2004.

10. Gupta AK, Gover MD and Lynde CW: Pulse itraconazole vs. continuous terbinafine for the treatment of dermatophyte toenail onychomycosis in patients with diabetes mellitus. J Eur Acad Dermatol Venereol 20: 1188-1193, 2006.

11. Tsubamoto H, Ueda T, Inoue K, Sakata K, Shibahara H and Sonoda T: Repurposing itraconazole as an anticancer agent. Oncol Lett 14: 1240-1246, 2017.

12. Navarro-Martínez MD, Cabezas-Herrera J and RodríguezLópez JN: Antifolates as antimycotics? Connection between the folic acid cycle and the ergosterol biosynthesis pathway in Candida albicans. Int J Antimicrob Agents 28: 560-567, 2006.

13. Pace JR, DeBerardinis AM, Sail V, Tacheva-Grigorova SK, Chan KA, Tran R, Raccuia DS, Wechsler-Reya RJ and Hadden MK: Repurposing the clinically efficacious Anti-fungal agent itraconazole as an anti-cancer chemotherapeutic. J Med Chem 59: 3635-3649, 2016.

14. Hu Q, Hou YC, Huang J, Fang JY and Xiong H: Itraconazole induces apoptosis and cell cycle arrest via inhibiting Hedgehog signaling in gastric cancer cells. J Exp Clin Cancer Res 36: 50, 2017.

15. Choi YH, Lee U, Lee BK and Lee MG: Pharmacokinetic interaction between itraconazole and metformin in rats: Competitive inhibition of metabolism of each drug by each other via hepatic and intestinal CYP3A1/2. Br J Pharmacol 161: 815-829, 2010.

16. Bondarenko LB, Shayakhmetova GM, Voronina AK and Kovalenko VM: Effects of metformin on cytochromes CYP3A, CYP2C and CYP2E1 Functioning at metabolic syndrome in rats of different age. Curr Res Diabetes Obes J 4: 555645, 2017.

17. Pakkir Maideen NM, Jumale A and Balasubramaniam R: Drug interactions of metformin involving drug transporter proteins. Adv Pharm Bull 7: 501-505, 2017.

18. Wagner DJ, Hu T and Wang J: Polyspecific organic cation transporters and their impact on drug intracellular levels and pharmacodynamics. Pharmacol Res 111: 237-246, 2016.

19. König J, Müller F and Fromm MF: Transporters and drug-drug interactions: Important determinants of drug disposition and effects. Pharmacol Rev 65: 944-966, 2013.

20. Quesada J and Amato R: The molecular biology of Soft-tissue sarcomas and current trends in therapy. Sarcoma 2012: 849456, 2012.

21. Anderson JL, Denny CT, Tap WD and Federman N: Pediatric sarcomas: Translating molecular pathogenesis of disease to novel therapeutic possibilities. Pediatr Res 72: 112-121, 2012.

22. Issaq SH, Teicher BA and Monks A: Bioenergetic properties of human sarcoma cells help define sensitivity to metabolic inhibitors. Cell Cycle 13: 1152-1161, 2014.

23. Hoang NT, Acevedo LA, Mann MJ and Tolani B: A review of soft-tissue sarcomas: Translation of biological advances into treatment measures. Cancer Manag Res 10: 1089-1114, 2018.
24. Burningham Z, Hashibe M, Spector L and Schiffman JD: The epidemiology of sarcoma. Clin Sarcoma Res 2: 14, 2012.

25. Calvert GT, Randall RL, Jones KB, Cannon-Albright L, Lessnick S and Schiffman JD: At-Risk populations for osteosarcoma: The syndromes and beyond. Sarcoma 2012: 152382, 2012.

26. Egas-Bejar D and Huh WW: Rhabdomyosarcoma in adolescent and young adult patients: Current perspectives. Adolesc Health Med Ther 5: 115-125, 2014.

27. Stoker M and Macpherson I: Syrian hamster fibroblast cell line BHK21 and its derivatives. Nature 203: 1355-1357, 1964.

28. Mayo J, Lombardo L, Klein-Szanto AJ, Conti CJ and Moreira JL: An oncogenic virus carried by hamster kidney cells. Cancer Res 33: 2273-2277, 1973.

29. Tomayko MM and Reynolds CP: Determination of subcutaneous tumor size in athymic (nude) mice. Cancer Chemother Pharmacol 24: 148-154, 1989.

30. Sápi J, Kovács L, Drexler DA, Kocsis P, Gajári D and Sápi Z: Tumor volume estimation and quasi-continuous administration for most effective bevacizumab therapy. PLoS One 10: e0142190, 2015.

31. Kanto K, Ito H, Noso S, Babaya N, Hiromine Y, Taketomo Y, Toma J, Niwano F, Yasutake S, Kawabata Y and Ikegami H: Effects of dosage and dosing frequency on the efficacy and safety of high-dose metformin in Japanese patients with type 2 diabetes mellitus. J Diabetes Investig: Sep 30, 2017 (Epub ahead of print).

32. de Sousa ATO, Vasconcelos JMB and Soares MJGO: Software Image Tool 3.0 as an instrument for measuring wounds. J Nurs UFPE on line 6: 2569-2573, 2012 (In English; Portuguese).

33. Scudiero DA, Shoemaker RH, Paull KD, Monks A, Tierney S, Nofziger TH, Currens MJ, Seniff D and Boyd MR: Evaluation of a soluble tetrazolium/formazan assay for cell growth and drug sensitivity in culture using human and other tumor cell lines. Cancer Res 48: 4827-4833, 1988.

34. Campbell BC, Chan KL and Kim JH: Chemosensitization as a means to augment commercial antifungal agents. Front Microbiol 3: 79, 2012.

35. Singh V and Singh SM: Effect of high cell density on the growth properties of tumor cells: A role in tumor cytotoxicity of chemotherapeutic drugs. Anticancer Drugs 18: 1123-1132, 2007.

36. No authors listed: (P097) tumor density, size, and histology in the outcome of stereotactic body radiation therapy for earlystage non-small-cell lung cancer: a single-institution experience. Oncology (Williston Park) 29 (Suppl 1): pii: 205053, 2015.

37. Dowling RJ, Lam S, Bassi C, Mouaaz S, Aman A, Kiyota T, Al-awar R, Goodwin PJ and Stambolic V: Metformin pharmacokinetics in mouse tumors: Implications for human therapy. Cell Metab 23: 567-568, 2016.

38. Cheong JH, Park ES, Liang J, Dennison JB, Tsavachidou D, Nguyen-Charles C, Wa Cheng K, Hall H, Zhang D, Lu Y, et al: Dual inhibition of tumor energy pathway by 2 -deoxyglucose and metformin is effective against a broad spectrum of preclinical cancer models. Mol Cancer Ther 10: 2350-2362, 2011.

39. Kim J, Tang JY, Gong R, Kim J, Lee JJ, Clemons KV, Chong CR, Chang KS, Fereshteh M, Gardner D, et al: Itraconazole, a commonly used antifungal that inhibits Hedgehog pathway activity and cancer growth. Cancer Cell 17: 388-399, 2010.

40. Choi CH, Ryu JY, Cho YJ, Jeon HK, Choi JJ, Ylaya K, Lee YY, Kim TJ, Chung JY, Hewitt SM, et al: The anti-cancer effects of itraconazole in epithelial ovarian cancer. Sci Rep 7: 6552, 2017.

41. Zhang L, Liu Z, Yang K, Kong C, Liu C, Chen H, Huang J and Qian F: Tumor progression of non-small cell lung cancer controlled by albumin and Micellar nanoparticles of Itraconazole, a Multitarget angiogenesis inhibitor. Mol Pharm 14: 4705-4713, 2017.

42. Hwang YP and Jeong HG: Metformin blocks migration and invasion of tumour cells by inhibition of matrix metalloproteinase- 9 activation through a calcium and protein kinase Calpha-dependent pathway: Phorbol-12-myristate-13-acetate-induced/extracellular signal-regulated kinase/activator protein-1. Br J Pharmacol 160: $1195-1211,2010$

This work is licensed under a Creative Commons Attribution-NonCommercial-NoDerivatives 4.0 International (CC BY-NC-ND 4.0) License. 